\title{
What caused Earth's temperature variations during the last 800,000 years? Data-based evidence on radiative forcing and constraints on climate sensitivity
}

\author{
Peter Köhler* \\ Alfred Wegener Institute for Polar and Marine Research, PO Box 120161, D-27515 Bremerhaven, Germany \\ Richard Bintanja \\ KNMI Royal Netherlands Meteorological Institute, Wilhelminalaan 10, 3732 GK De Bilt, Netherlands \\ Hubertus Fischer \\ Climate and Environmental Physics, Physics Institute, University of Bern, Sidlerstr. 5, 3012 Bern, Switzerland \\ Oeschger Centre for Climate Change Research, University of Bern, Erlachstrasse 9a, 3012 Bern, Switzerland
}

Fortunat Joos

Climate and Environmental Physics, Physics Institute, University of Bern, Sidlerstr. 5, 3012 Bern, Switzerland

Oeschger Centre for Climate Change Research, University of Bern, Erlachstrasse 9a, 3012 Bern, Switzerland

Reto Knutti

Institute for Atmospheric and Climate Science, ETH Zürich, Ch-8092 Zürich, Switzerland

Gerrit Lohmann

Alfred Wegener Institute for Polar and Marine Research, PO Box 120161, D-27515 Bremerhaven, Germany

Valérie Masson-Delmotte

Laboratoire des Sciences du Climat et de l'Environnement, IPSL/CEA-CNRS-UVSQ, UMR 1572, Bat 701, L'Orme des Merisiers CEA, Saclay, 91 191 Gif-sur-Yvette CEDEX, France

\begin{abstract}
The temperature on Earth varied largely in the Pleistocene from cold glacials to interglacials of different warmths. To contribute to an understanding of the underlying causes of these changes we compile various environmental records (and model-based interpretations of some of them) in order to calculate the direct effect of various processes on Earth's radiative budget and, thus, on global annual mean surface temperature over the last 800,000 years. The importance of orbital variations, of the greenhouse gases $\mathrm{CO}_{2}, \mathrm{CH}_{4}$ and $\mathrm{N}_{2} \mathrm{O}$, of the albedo of land ice sheets, annual mean snow cover, sea ice area and vegetation, and of the radiative perturbation of mineral dust in the atmosphere are investigated. Altogether we can explain with these processes a global cooling of $3.9 \pm 0.8 \mathrm{~K}$ in the equilibrium temperature for the Last Glacial Maximum (LGM) directly from the radiative budget using only the Planck feedback that parametrises the direct effect on the radiative balance, but neglecting other feedbacks such as water vapour, cloud cover, and lapse rate. The unaccounted feedbacks and related uncertainties would, if taken at present day feedback strengths, decrease the global temperature at the LGM by $-8.0 \pm 1.6 \mathrm{~K}$. Increased Antarctic temperatures during the Marine Isotope Stages 5.5, 7.5, 9.3 and 11.3 are in our conceptual approach difficult to explain. If compared with other studies, such as PMIP2, this gives supporting evidence that the feedbacks themselves are not constant, but depend in their strength on the mean climate state. The best estimate and uncertainty for our reconstructed radiative forcing and LGM cooling support a present day equilibrium climate sensitivity (excluding the ice sheet and vegetation components) between 1.4 and $5.2 \mathrm{~K}$, with a most likely value near $2.4 \mathrm{~K}$, somewhat smaller than other methods but consistent with the consensus range of $2-4.5 \mathrm{~K}$ derived from other lines of evidence. Climate sensitivities above $6 \mathrm{~K}$ are difficult to reconcile with Last Glacial Maximum reconstructions.
\end{abstract}

Key words: radiative forcing, temperature, Pleistocene, greenhouse gases, albedo, climate sensitivity 


\section{Introduction}

Natural climate variations during the Pleistocene are still not fully understood. Neither do we know how much the Earth's annual mean surface temperature changed in detail, nor which processes were responsible for how much of these temperature variations. Although our understanding based on climate models is steadily increasing most studies are focused on individual time periods such as the Last Glacial Maximum (LGM) to facilitate inter-comparison between different models and with data compilations, and do not consider temporal changes over longer time scales (e.g. Braconnot et al., 2007a,b).

Greenhouse gas (GHG) emissions, especially of $\mathrm{CO}_{2}$, are nowadays known with very high confidence to be responsible for the anthropogenic temperature rise (Solomon et al., 2007), but were also suggested to be responsible for part of the warming during glacial/interglacial transitions (Genthon et al., 1987; Lorius et al., 1990). However, the direct effect of $\mathrm{CO}_{2}$ via its changes of the radiative budget on temperature is much smaller than the reconstructed changes in temperature. Climate models are therefore used to calculate the overall response of Earth's climate to a certain forcing such as a change in $\mathrm{CO}_{2}$ (e.g. Charney et al., 1979; Hansen et al., 2008; Knutti et al., 2008; Plattner et al., 2008; Vuuren et al., 2008). From the comparison of the direct effect of $\mathrm{CO}_{2}$ on temperature and other global radiative perturbations with the measured or simulated changes an amplification or feedback factor is calculated (Genthon et al., 1987; Lorius et al., 1990; Hansen et al., 1984, 2007, 2008). In this respect equilibrium climate sensitivity is typically used as the global mean near surface temperature rise towards a new steady state resulting from a doubling of the atmospheric $\mathrm{CO}_{2}$ content (therefore also called $\Delta T_{2 \times \mathrm{CO}_{2}}$ ). $\Delta T_{2 \times \mathrm{CO}_{2}}$ depends on the climate model and the implementation of processes of the different climate feedbacks therein. Recent model-based estimates vary by more than a factor of two between $2.1 \mathrm{~K}$ and $4.4 \mathrm{~K}$ for future climate change (Knutti et al., 2006; Kiehl, 2007; Randall et al., 2007; Knutti and Hegerl, 2008; Plattner et al., 2008), but some cases also include much higher values of up to $11 \mathrm{~K}$ (e.g. Stainforth et al., 2005). For the climate of the LGM a similar climate sensitivity of $1.2-4.3 \mathrm{~K}$ was proposed based on an Earth system model of intermediate complexity (Schneider von Deimling et al., 2006a), and values up to $6 \mathrm{~K}$ were found in an atmosphere general circulation model coupled to a slab ocean model (Annan et al., 2005). However, more complex models suggest that the climate sensitivity for the LGM and the present climate may differ substantially (Crucifix, 2006; Edwards et al., 2007; Hargreaves et al., 2007). The conceptual approach behind these model-based analyses is that most (if not all) globally important processes are included in the climate model used in order to calculate an appropriate response to given changes in the forcing. This approach is limited to selected time periods, especially if full general circulation models are used, because of computational high costs and because sufficient empirical data are necessary to calibrate these models (e.g. Edwards et al., 2007).

\footnotetext{
* Corresponding author

Email addresses: peter.koehler@awi.de (Peter Köhler) $U R L$ : www . awi. de (Peter Köhler)
}

Here, we focus on changes in the global annual mean radiative budget, which can be calculated for different processes from existing data sets for the past. Changes in the radiative forcing of the $\mathrm{GHG} \mathrm{CO}_{2}, \mathrm{CH}_{4}$, and $\mathrm{N}_{2} \mathrm{O}$ during the last glacial/ interglacial transition were already calculated with high accuracy using ice core data (Joos and Spahni, 2008). It is found that the current rise in forcing from these gases occurs one to two orders of magnitude faster than century scale changes in the past 20,000 years. The scientific understanding of the direct effect of these GHG on climate is high, while the knowledge on other important processes is much lower (Jansen et al., 2007). However, even with this lack of knowledge it is worthwhile to combine what we know about changes in the climate system over time into a first tentative compilation. So far the climatic response to $\mathrm{CO}_{2}$ and orbital forcing was calculated over the last glacial cycle using a linear multivariate analysis (Genthon et al., 1987), concluding that the direct effect of lower $\mathrm{CO}_{2}$ during the LGM could only account for a temperature anomaly $\Delta T$ of $-0.6 \mathrm{~K}$, and an amplification factor of $5-14$ was necessary for the explanation of reconstructed $\Delta T$ derived from the Vostok ice core stable isotope data. Hansen et al. (1984) calculated the specific feedbacks of individual processes on Earth's radiative budget with a general circulation model for the LGM climate. Many recent studies relate past temperature changes to the observed variations in GHG (e.g. Hansen et al., 2007, 2008). These approaches are limited in the sense that all additional changes in temperature are linearly related to the $\mathrm{CO}_{2}$ changes and hidden in the feedback factors, which are so far assumed to be constant.

Our study compiles changes in Earth's global radiation budget on longer timescales and the importance of the other processes besides GHG. We focus on the last 800,000 years ( $800 \mathrm{kyr}$ ), the time window covered by the European Project for Ice Coring in Antarctica (EPICA) ice core from Dome C, where reliable records of GHG and of other climate variables (such as aeolian dust concentration) are available. Our goal is to use the available proxy records and to calculate the direct contributions of individual processes to changes in Earth's radiative budget and to the global annual mean surface air temperature (SAT). This approach enables us to identify how much temperature change can be explained with our observational knowledge and how important additional feedbacks might have operated in the past. We finally discuss how our compilation on changes in radiative forcing during the LGM constrains quantitatively the equilibrium climate sensitivity.

\section{Earth's radiative balance}

If the Earth is in radiative equilibrium then the incoming short-wave (SW) radiation $I$ from the sun reaching the Earth has to be balanced by the outgoing long-wave (LW) radiation $R$ according to Earth's equilibrium temperature $T_{E}$ following the Stefan-Boltzmann law $\left(R_{0}=\sigma T_{E}^{4}, \sigma=5.67 \times 10^{-8} \mathrm{~W} \mathrm{~m}^{-2} \mathrm{~K}^{-4}\right)$. In this radiative balance the reflectance and absorption within the atmosphere also needs to be considered (Fig. 1). The incoming radiation $I$ depends spatially and temporally on the orbital configurations of the Earth (Berger, 1978), but is mainly determined by the solar constant $S$, whose average $\pm 1 \sigma$ over the years 1978-2005 is $1366.0 \pm 0.6 \mathrm{~W} \mathrm{~m}^{-2}$ (Fröhlich, 2006). 
Nearly a third of the incoming radiation is reflected back to space, determined by the planetary albedo of $\alpha_{P}=0.30$ (Goode et al., 2001; Pallé et al., 2005; Wielicki et al., 2005). The atmosphere accounts for the majority $(>75 \%)$ of the planetary albedo, but the temporal variability of $\alpha_{P}$ is mainly determined by surface processes (Qu and Hall, 2005). The present day surface albedo used here $\left(\alpha_{S}=0.15\right)$ is calculated from the given atmospheric reflection $\alpha_{A}=0.212$ and absorption $a=0.2$ (Kiehl and Trenberth, 1997) to match the satellite-derived $\alpha_{P}$. We furthermore assume a mean ocean albedo $\left(\alpha_{o}=0.10\right)$, sea ice albedo $\left(\alpha_{S I}=0.55\right)$, and land ice albedo $\left(\alpha_{L I}=0.75\right)$ (Payne, 1972; Stroeve et al., 2001; Qu and Hall, 2005; Fitzpatrick and Warren, 2007) from which the residual albedo of ice-free land $\left(\alpha_{L}=0.20\right)$ is determined, which is in line with observations (Wanner et al., 1997). SW radiation reflected from the surface is assumed to reach the top of the atmosphere (TOA) without any further interaction within the atmosphere. In this respect our approach is simpler than others (e.g. Taylor et al., 2007). GHG are finally absorbing about $40 \%$ of the outgoing LW radiation, implying that the effective emissivity of the Earth is $\varepsilon=0.60$ and $R=\varepsilon R_{0}$. Sixty percent of this GHG effect are accounted for by water vapour (Kiehl and Trenberth, 1997). This simplistic annual mean view of Earth's radiation budget sketched in Fig. 1 contains the level of detail we address in this article. Temporal variations in the above mentioned variables supported by data- and model-based approaches can then give information about Earth's radiative balance and, thus, global annual mean temperature change in the past.

The radiative balance is altered by (a) variations in the incoming solar radiation, (b) variations in the GHG concentration, (c) variations in the planetary albedo and (d) the additional contributions from the feedback processes. The incoming solar radiation itself varies due to changes in the solar constant $S$, i.e. the energy output from the sun, and due to Earth's orbital variations. Milankovitch (1941) proposed that the latter is the driver for Quaternary climate change, which was later on supported by analyses of the geological records (Hays et al., 1976). Other studies suggested that the glacial/interglacial cycles result from the Earth's internal climate variability and are phase locked on orbital forcing (e.g. Saltzman et al., 1984). Orbital variations influence the local insolation and the seasonal cycle, but lead to only small changes of less than $0.5 \mathrm{~W} \mathrm{~m}^{-2}$ in the global annual mean insolation with periodicities of 100 and 400 kyr caused by eccentricity (Berger, 1978).

The magnitude of solar irradiance variations over the past millennia (or the past million years) is not well known. Only small changes in solar irradiance are apparent in the satellite records of the past 30 years with no apparent long-term trend (Foukal et al., 2006; Fröhlich, 2006). Extension of irradiance changes back in time used evidence of changing sunspot numbers and cosmogenic isotope production. There is general agreement in the evolution of different proxy records of solar activity (Muscheler et al., 2007; Wanner et al., 2008). However, the relationship between the isotopic records, indicative of the Sun's open magnetic field, sunspot numbers and solar energy output are not well understood. In previous reconstructions, total irradiance during the last millennium was estimated to be 0.15 to $0.65 \%$ (radiative forcing about -0.36 to $-1.55 \mathrm{~W} \mathrm{~m}^{-2}$ ) below the present day-mean (e.g. Bard et al., 2000), whereas other work suggest a reduction of only about $0.1 \%$ in solar energy output (e.g. Wang et al., 2005). Over the last 4.5 billion years the sun's energy output increased by $40 \%$ (Sagan and Mullen, 1972). In our time window of interest this effect is less than $0.05 \mathrm{~W} \mathrm{~m}^{-2}$ and therefore negligible. Furthermore, the way the sun affects Earth's climate is not fully understood (Rind, 2002). Besides changes in the total solar irradiance (determining $S$ ), the influence of UV irradiance on the troposphere and cosmic rays modulating the production of clouds have been proposed (Lockwood and Fröhlich, 2007, 2008; Lockwood, 2008). Evidence for these different hypotheses is sparse and in the absence of a better understanding on Quaternary solar variability we keep $S$ constant in time in the following calculations, but use its estimated variability over the last centuries as estimated uncertainty range of the solar influence on the incoming radiation $I\left(\sigma_{I}=0.2 \%\right)$.

Climate feedbacks operate on different time scales. Slow feedbacks are processes whose response to a change in forcing takes significantly longer than a century. An example is ice sheet melting and associated sea level changes and eustatic adjustments. Changes in ice sheet extent (and in other slow feedbacks) are typically ignored in projections of $21^{\text {st }}$ century climate change or in equilibrium simulations for the LGM and a time-invariant ice sheet is prescribed according to present day or reconstructed LGM conditions. Processes operating with response times of up to a few years may be called fast feedbacks. Fast feedbacks are changes in water vapour, lapse rate variations, cloud cover, and sea-ice. These feedbacks are explicitly included in state-of-the art climate models. Changes in vegetation distribution and related changes in the aerosol content of the atmosphere respond to changes in forcing and climate on a decadal-to-century time scale. In the past, vegetation distribution has been prescribed in models, but simulations with interactive vegetation cover are now becoming more common (e.g. Friedlingstein et al., 2006; Plattner et al., 2008).

Water vapour and lapse rate influence the absorption of radiation in the atmosphere, while land and sea ice, vegetation, and aerosols mainly influence the albedo. Clouds affect both the albedo and the GHG effect, but the net modern result of clouds is a cooling, meaning that the albedo effect is stronger than the GHG effect of water vapour for the present climate state (Ramanathan and Inamdar, 2006). For present day and future climate a much longer list of forcing agents is considered (Forster et al., 2007). However, these additional agents are either not important in preindustrial climates, because they were introduced by mankind only in the last century (e.g. halocarbons), or we have such poor understanding of their impact on climate and lack information about their variability in the past (e.g. indirect effect of aerosols (Anderson et al., 2003; Lohmann and Feichter, 2005; Lohmann et al., 2007)).

Changes in the radiative budget lead to a new long-term steady-state with a temperature change $\Delta T_{E, \infty}$. It can be calculated from a feedback analysis (for further details, see e.g. Dufresne and Bony, 2008), for which one needs to consider that any radiative flux perturbation $\Delta R$ will be amplified by the feedbacks in the climate system, thus

$$
\Delta T_{E, \infty}=\frac{-\Delta R}{\lambda}
$$

where $\lambda$ is the climate feedback parameter, and the fluxes are 
positive downward. The feedback parameter is commonly split in the sum of different terms,

$$
\lambda=\lambda_{P}+\lambda_{W V}+\lambda_{L R}+\lambda_{C},
$$

which are the Planck (P), water vapour (WV), lapse rate (LR), and cloud (C) feedback parameters. Normally, another feedback parameter for surface albedo $\left(\lambda_{\alpha}\right)$ is considered, but because we try to estimate albedo changes from reconstructions its contribution is accounted for in the forcing terms. We will combine in our final compilation the water vapour, lapse rate, and cloud feedbacks to one feedback with $\lambda_{\text {else }}=\lambda_{W V}+$ $\lambda_{L R}+\lambda_{C}$.

The feedback parameters for water vapour, lapse rate, and clouds can only be estimated with climate models (but see Farrera et al. (1999) for data-based assumptions on the LGM lapse rate), while the Planck feedback parameter $\lambda_{P}$ and the corresponding equilibrium temperature change $\Delta T_{E, P}$ can be calculated from the derivative of $R=\varepsilon R_{0}$ :

$$
\Delta R=\left.\frac{\delta R}{\delta T}\right|_{T=T_{E}} \cdot \Delta T_{E, P} \text { with } \frac{\delta R}{\delta T}=4 \varepsilon \sigma T^{3} .
$$

$T_{E}=286.5 \mathrm{~K}$ is the preindustrial temperature, which is about $0.5 \mathrm{~K}$ less than the mean of the years 1961-1990 (Jones et al., 1999; Brohan et al., 2006). This leads to the Planck feedback parameter $\lambda_{P}$,

$$
\lambda_{P}=\frac{-\Delta R}{\Delta T_{E, P}}=-3.2 \frac{\mathrm{Wm}^{-2}}{\mathrm{~K}},
$$

or the specific climate sensitivity without further feedbacks $s_{P}=$ $-1 / \lambda_{P}$ of

$$
s_{P}=\frac{\Delta T_{E, P}}{\Delta R}=0.3125 \frac{\mathrm{K}}{\mathrm{Wm}^{-2}} .
$$

The specific climate sensitivity without feedbacks $s_{P}$ will be used in the following to calculate the temperature anomaly of the Planck feedback $\Delta T_{E, P}$ of perturbations in the radiative budget. Other feedbacks and interactive effects are, thus, first ignored, but will be discussed in Section 3.4.

\section{The individual processes}

We estimate an uncertainty for all assumptions and data sources, based on our arguably subjective assessment of the reliability of data- and model-based reconstructions of certain climate variables. Calculated effects on the radiative budget are therefore a combination of our best guess $\Delta R$ and an uncertainty range attached to it. All data sets are resampled with an equidistant temporal spacing of 100 years. An overview of the assumed uncertainties and the results for the LGM (averages over 23 - 19 kyr BP as defined by EPILOG (Mix et al., 2001)) is compiled in Table 1. We assume the uncertainties to be one standard deviation $(1 \sigma)$. Error propagation of uncertainties of several different parameters within one process is calculated by the square root of the sum of squares of individual uncertainties assuming independency between the single parameters. Furthermore, a lower estimate of a total error for a combination of different processes (e.g. $\Delta R$ of all processes or of all GHG) is also calculated using the same approach. However, as some processes certainly depend on each other (e.g. vegetation and
$\mathrm{CO}_{2}$ evolution) we also calculate an upper estimate of the uncertainty for combined processes by adding the individual uncertainties together.

\subsection{Greenhouse gases}

Although water vapour is the most important GHG (Kiehl and Trenberth, 1997; Ramanathan and Inamdar, 2006), the following compilation does not consider any changes in water vapour in the past due to missing constraints on its variability. Some estimates on water vapour feedbacks are given in Section 3.4. We concentrate here on the $\mathrm{GHG} \mathrm{CO}, \mathrm{CH}_{4}$, and $\mathrm{N}_{2} \mathrm{O}$. Carbon dioxide and $\mathrm{CH}_{4}$ are measured with a mean temporal resolution better than $1 \mathrm{kyr}$ in ice cores over the last $800 \mathrm{kyr}$, but $\mathrm{N}_{2} \mathrm{O}$ exhibits large time windows with no or biased data sets (Petit et al., 1999; Monnin et al., 2001; Siegenthaler et al., 2005; Spahni et al., 2005; Loulergue et al., 2008; Lüthi et al., 2008). $\mathrm{CO}_{2}$ varies between 170 and 300 ppmv, the variations in $\mathrm{CH}_{4}$ and $\mathrm{N}_{2} \mathrm{O}$ are three orders of magnitude smaller (Fig. 2A). However, their impact on the radiative balance per mol gas is larger than that of $\mathrm{CO}_{2}$. We use simplified expressions for the calculation of the direct radiative forcing of $\mathrm{CO}_{2}, \mathrm{CH}_{4}$, and $\mathrm{N}_{2} \mathrm{O}$ (Myhre et al., 1998):

$$
\begin{aligned}
\Delta R_{\mathrm{CO}_{2}} & =5.35 \cdot \ln \left(\frac{\mathrm{CO}_{2}}{\mathrm{CO}_{2,0}}\right) \\
\Delta R_{\mathrm{CH}_{4}}^{0} & =0.036 \cdot\left(\sqrt{\mathrm{CH}_{4}}-\sqrt{\mathrm{CH}_{4,0}}\right) \\
\Delta R_{\mathrm{N}_{2} \mathrm{O}}^{0} & =0.12 \cdot\left(\sqrt{\mathrm{N}_{2} \mathrm{O}}-\sqrt{\mathrm{N}_{2} \mathrm{O}_{0}}\right)
\end{aligned}
$$

All $\Delta R$ 's are given in $\mathrm{W} \mathrm{m}^{-2}, \mathrm{CO}_{2}$ in ppmv, $\mathrm{CH}_{4}$ and $\mathrm{N}_{2} \mathrm{O}$ in ppbv, $\mathrm{CO}_{2,0}=278$ ppmv, $\mathrm{CH}_{4,0}=742$ ppbv and $\mathrm{N}_{2} \mathrm{O}_{0}=$ $272 \mathrm{ppbv}$, where the superscript zero $\left(\Delta R^{0}\right)$ denotes an approach, which will be refined further below. A term for the interactive absorption effects between $\mathrm{CH}_{4}$ and $\mathrm{N}_{2} \mathrm{O}$ is omitted here. It would lead to corrections in $\Delta R_{\mathrm{CH}_{4}}^{0}$ and $\Delta R_{\mathrm{N}_{2} \mathrm{O}}^{0}$ of the order of a few $0.01 \mathrm{~W} \mathrm{~m}^{-2}$. To account for the higher efficacy of $\mathrm{CH}_{4}$ relative to $\mathrm{CO}_{2}$, which is due mainly to the indirect effects of $\mathrm{CH}_{4}$ on stratospheric $\mathrm{H}_{2} \mathrm{O}$ and tropospheric $\mathrm{O}_{3}$ (Hansen et al., 2005) an additional change of $40 \%$ in $\Delta R_{\mathrm{CH}_{4}}$ has to be considered (Hansen et al., 2008), thus $\Delta R_{\mathrm{CH}_{4}}=$ 1.4 $\cdot \Delta R_{\mathrm{CH}_{4}}^{0}$. The $\mathrm{N}_{2} \mathrm{O}$ record contains large data gaps due to artefacts probably produced by high dust content during glacial periods (Flückiger et al., 2004). $\mathrm{N}_{2} \mathrm{O}$ measurements during times with dust concentrations in Antarctic ice cores larger than 300 ppbw are considered to be disturbed by artifacts and excluded from the record (Spahni et al., 2005). We therefore use in the following the approach of Hansen et al. (2008) and a formulation to estimate continuously the radiative forcing of $\mathrm{N}_{2} \mathrm{O}$ which is based on the combined effect from $\mathrm{CO}_{2}$ and $\mathrm{CH}_{4}$ leading to $\Delta R_{\mathrm{N}_{2} \mathrm{O}}=0.12 \cdot\left(\Delta R_{\mathrm{CO}_{2}}+\Delta R_{\mathrm{CH}_{4}}\right)$. This rather crude approach assumes a linear relationships between $\mathrm{N}_{2} \mathrm{O}$ and the other two GHG, and might therefore impose an error on $\Delta R_{\mathrm{N}_{2} \mathrm{O}}$. However the uncertainty in our final calculation is limited due to the small effect of $\mathrm{N}_{2} \mathrm{O}$. Furthermore, latest measurements of $\mathrm{N}_{2} \mathrm{O}$ in the so far uncovered time windows 250-450 and 650-800 kyr BP confirm that $\mathrm{N}_{2} \mathrm{O}$ varies between 200 and 300 ppbv (Schilt et al., 2009).

The error propagation of the GHG considers the measurement uncertainties in $\mathrm{CO}_{2}$ and $\mathrm{CH}_{4}\left(\sigma_{\mathrm{CO}_{2}}=2 \mathrm{ppmv}\right.$ (Petit et al., 1999; Siegenthaler et al., 2005); $\sigma_{\mathrm{CH}_{4}}=10 \mathrm{ppbv}$, (Spahni 
et al., 2005)), the relative uncertainty of Eq. 6 and $7\left(\sigma_{R}=\right.$ $10 \%$ (Forster et al., 2007)), and in the case of $\mathrm{CH}_{4}$ additionally the uncertainty of the efficacy $\left(\sigma_{\text {efficacy }}=5 \%\right.$ (Hansen et al., 2005)) and of the interaction with $\mathrm{N}_{2} \mathrm{O}\left(\sigma_{\text {inter }_{2} \mathrm{O}}=\right.$ $0.02 \mathrm{~W} \mathrm{~m}^{-2}$ ). For $\Delta R_{\mathrm{N}_{2} \mathrm{O}}$ we only consider a global error of $\sigma_{R}=0.1 \mathrm{~W} \mathrm{~m}^{-2}$ because $\Delta R_{\mathrm{N}_{2} \mathrm{O}}$ does not depend on underlying physics, but is only estimated roughly from $\mathrm{CO}_{2}$ and $\mathrm{CH}_{4}$.

The radiative forcing of all three GHG is apart from the peak interglacials MIS 5.5, 7.5, 9.3 and 11.3 always negative with minima of $-2.6,-0.4$ and $-0.3 \mathrm{~W} \mathrm{~m}^{-2}$ for $\Delta R_{\mathrm{CO}_{2}}$, $\Delta R_{\mathrm{CH}_{4}}$ and $\Delta R_{\mathrm{N}_{2} \mathrm{O}}$, respectively (Fig. 2B). Positive deviations during the interglacials mentioned above are negligible for $\mathrm{CH}_{4}$ and $\mathrm{N}_{2} \mathrm{O}$ and smaller than $+0.4 \mathrm{~W} \mathrm{~m}^{-2}$ for $\mathrm{CO}_{2}$. The forcing for $\mathrm{N}_{2} \mathrm{O}$ based on $\mathrm{N}_{2} \mathrm{O}$ data only (Eq. 8) is nearly always smaller than its estimate derived from $\mathrm{CO}_{2}$ and $\mathrm{CH}_{4}$. Altogether the total forcing from GHG $\Delta R_{\mathrm{GHG}}$ is dominated by $\mathrm{CO}_{2}$. The maximum effect during most peak glacial periods is around -2.5 to $-3.0 \mathrm{~W} \mathrm{~m}^{-2}$ with the absolute minimum of $-3.3 \mathrm{~W} \mathrm{~m}^{-2}$ around $670 \mathrm{kyr} \mathrm{BP}$. The temperature anomalies $\Delta T_{E, P}$ considering only the Planck feedback caused by the three $\mathrm{GHG}$ are up to -0.9 to $-1.0 \mathrm{~K}$ for peak glacial times and warming of less than $+0.2 \mathrm{~K}$ during the last interglacials (Fig. 2B).

\subsection{Surface albedo}

In order to calculate the perturbation in the radiative balance due to various processes affecting surface albedo (land ice sheets, shelves exposed by sea level drop, sea ice, snow cover, vegetation distribution) we compile in the following, how (i) local annual mean insolation (which varies mainly due to obliquity), (ii) the areal coverage, and (iii) the albedo of various compartments change in their annual mean values over the last 800 kyr. The uncertainties in areal coverage and albedo changes are given individually for the different processes, while the uncertainty in local annual mean insolation is assumed to be represented by the uncertainty in the solar constant $\sigma_{I}$. Based on our simplistic view of Earth's radiative budget we can, thus, calculate $\Delta R$ connected with those processes.

\subsubsection{Land cryosphere}

Continental ice sheets in North America and Eurasia covered an area of up to $17 \times 10^{12} \mathrm{~m}^{2}$ during glacial maxima (Fig. 3B). This was deconvoluted from the deep ocean benthic $\delta^{18} \mathrm{O}$ stack LR04 (Bintanja et al., 2005; Bintanja and van de Wal, 2008; Lisiecki and Raymo, 2005). The deconvolution of the LR04 benthic $\delta^{18} \mathrm{O}$ stack into different climate data is based on the fact that both the storage of $\delta^{18} \mathrm{O}$ in ice sheets and changes in ocean temperature affect the foraminiferal calcite $\delta^{18} \mathrm{O}$. Both processes are related to surface air temperature. Models describe these relationships: an ice-sheet model (Bintanja et al., 2002) that links air temperature to ice volume and $\delta^{18} \mathrm{O}$ stored in ice, and an ocean-temperature model (Bintanja and Oerlemans, 1996) that couples surface air temperature to deep ocean temperature. An inverse method deconvolves the two components of $\delta^{18} \mathrm{O}$ for the LR0 $\delta^{18} \mathrm{O}$ record leading to mutually consistent records of atmospheric temperature, ice volume, ice area, ice-free area, albedo on both ice and icefree land (all continents in the latitudinal band of $40-80^{\circ} \mathrm{N}$ ), deep ocean temperature and global sea level. The approach is based on the assumption that the fraction of $\delta^{18} \mathrm{O}$ that varies due to sea level changes is caused to $85 \%(15 \%)$ by the waxing and waning of the North American and Eurasian (Antarctic and Greenland) ice sheets (Bintanja et al., 2002).

The local annual mean insolation in the latitudinal band containing the northern hemispheric ice sheets varied between 267 and $271 \mathrm{~W} \mathrm{~m}^{-2}$ (Fig. 3A). The model of Bintanja et al. (2005) furthermore calculates, based on monthly snow cover simulations (Bintanja et al., 2002), that the surface albedo on the ice sheets was about 0.6 larger than on the ice-free continents (Fig. 3C). This information on area, albedo and insolation together with the fact, that the respective latitudinal band covers about $17 \%$ of Earth's surface are combined to calculate the radiative perturbation caused only by the albedo feedback of land ice sheets $\Delta R_{\text {ice }}$ (Fig. 3D). $\Delta R_{\text {ice }}$ is as large as $-3.2 \mathrm{~W} \mathrm{~m}^{-2}$ during glacial maxima, and always smaller than $+0.1 \mathrm{~W} \mathrm{~m}^{-2}$ during interglacials. We assume uncertainties of $\pm 10 \%$ in the ice sheet area and \pm 0.1 in the annual mean albedo on ice $\alpha_{L I}$ resulting in $-3.2 \pm 0.6 \mathrm{~W} \mathrm{~m}^{-2}$ in $\Delta R_{\text {ice }}$ for the LGM. The equilibrium temperature change $\Delta T_{E, P}$ computed from the Planck feedback and ice sheet-albedo forcing alone is $-1.0 \mathrm{~K}(-0.8$ to $-1.2 \mathrm{~K}$ ) during peak glacial times (Fig. 3D).

The uncertainty based on the error estimate is very small for interglacials, however other evidence (as mentioned in the following) point to an incomplete understanding of ice sheet dynamics during the interglacials MIS 5.5, 7.5, 9.3, and 11.3, which are warmer than the Holocene (called ,warm interglacials“ in the following), at least in Antarctic temperature reconstructions (Jouzel et al., 2007). For example, the approach of Bintanja et al. (2005) calculated significantly lower sea level high stands for MIS 7 than other approaches based on either $\delta^{18} \mathrm{O}$, coral, or submerged speleothems (Dutton et al., 2009). Part of the sea level rise above present during past interglacials, e.g. +3 to +6 m during MIS 5.5 (Stirling et al., 1998; Blanchon et al., 2009), might potentially be caused by thinning of the Greenland and Antarctic ice sheets. While models (Cuffey and Marshall, 2000; Otto-Bliesner et al., 2006) suggest a significant reduction in the areal extent of the Greenland ice sheets in MIS 5.5, ice cores give evidence that the Greenland ice sheet was at that time at least partially intact (Landais et al., 2003; Oerlemans et al., 2006). Pieces of evidence from pollen data (de Vernal and Hillaire-Marcel, 2008) suggest significantly larger forest vegetation (implying a smaller ice sheet) in Greenland especially in MIS 11.3. With $1.8 \times 10^{12} \mathrm{~m}^{2}$, the size of the present day Greenland ice sheet is about $10 \%$ of the suggested areal extent of the maximum northern hemispheric land ice sheets during the LGM (Peltier, 2004; Bintanja et al., 2005) and its potential shrinking might therefore contribute only little to a warmer than present climate on a global scale.

This waxing and waning of the northern hemispheric land ice sheets is directly connected with sea level variations. The sea level drop of 120 to $140 \mathrm{~m}$ during the LGM (Fairbanks, 1989; Yokoyama et al., 2000) exposed around $14 \times 10^{12} \mathrm{~m}^{2}$ of continental shelves to the atmosphere (Fig. 3B). This area estimate of exposed shelves is calculated for a sea level drop of $123 \mathrm{~m}$ (Bintanja et al., 2005) without consideration of isostatic adjustment from the global elevation data set (http://dss.ucar.edu/datasets/ds750.1). We consider an increase 
in albedo from ocean to land of 0.1 and assume an uniform distribution of coastal regions with latitude (implying the use of the global mean insolation of around $342 \mathrm{~W} \mathrm{~m}^{-2}$ ). This leads then to an additional radiative forcing of $\Delta R_{\text {sea level }}=-0.6 \mathrm{~W} \mathrm{~m}^{-2}$ at the LGM. Assumed uncertainties of $\pm 20 \%$ in the area and \pm 0.05 in albedo extend the range of the additional radiative forcing during glacial maxima to -0.3 to $-0.8 \mathrm{~W} \mathrm{~m}^{-2}$.

The combined effect of land ice sheet growth and sea level drop leads to an albedo feedback at the LGM of $-3.7 \mathrm{~W} \mathrm{~m}^{-2}$ with an upper estimated uncertainty range of -2.8 to $-4.6 \mathrm{~W} \mathrm{~m}^{-2}$ which is in reasonable agreement with $-3.2 \mathrm{~W} \mathrm{~m}^{-2}$ given by the IPCC AR4 (Jansen et al., 2007). The difference of $0.5 \mathrm{~W} \mathrm{~m}^{-2}$ between the IPCC and our best guess might be due to the uneven distribution of land ice with latitude during the LGM. Only very little land ice was probably located north of $70^{\circ} \mathrm{N}$ (e.g. Zweck and Huybrechts, 2005), while we here took the mean insolation over the $40-80^{\circ} \mathrm{N}$ band for our calculations.

The albedo effect of extended snow cover during glacial times on ice-free land can be estimated in terms of a forcing (in $\mathrm{W} \mathrm{m}^{-2}$ ) but in the framework of the climate sensitivity calculation below (Section 4.3) is treated as a feedback. For the role of snow in the climate system in general see Vavrus (2007). Again, simulation results of Bintanja et al. (2005) on changes in area and albedo (calculated by monthly mean snow cover (Bintanja et al., 2002)) in the latitudinal band $40-80^{\circ} \mathrm{N}$ are used to calculate an additional change in $\Delta R_{\text {snow }}$ of -1.5 to $+0.8 \mathrm{~W} \mathrm{~m}^{-2}$ (Fig. 3D). This approach assumes a surface albedo of 0.8 over snow leading to anomalies in the mean albedo on ice-free land at $40-80^{\circ} \mathrm{N}$ of +0.1 to -0.05 (Fig. 3C). The largest changes in $\Delta R_{\text {snow }}$ occur before those in $\Delta R_{\text {ice, }}$, reflecting that snow accumulates/melts prior to ice growth/decay. The assumed uncertainties in area $( \pm 10 \%)$ and albedo $( \pm 0.05)$ lead to an error range of about $\pm 0.6 \mathrm{~W} \mathrm{~m}^{-2}$ at the LGM. Snow cover on land south of $40^{\circ} \mathrm{N}$ might eventually also have an impact on albedo, but based on the present day seasonality in surface albedo $(\mathrm{Qu}$ and Hall, 2005) we estimate its effect to be rather small.

Altogether, the land cryosphere comprises an albedo forcing $\left(\Delta R_{\text {land cryo }}=\Delta R_{\text {ice }}+\Delta R_{\text {sea level }}+\Delta R_{\text {snow }}\right)$ which is at best -4.5 and $+0.8 \mathrm{~W} \mathrm{~m}^{-2}$ at the LGM and MIS 5.5 , respectively, but which within the uncertainties might also be as much as -3.0 to $-6.0 \mathrm{~W} \mathrm{~m}^{-2}$ (LGM) and 0.0 to $+1.6 \mathrm{~W} \mathrm{~m}^{-2}$ (MIS 5.5). The temperature anomaly $\Delta T_{E, P}$ resulting from the Planck feedback and this radiative forcing is $-1.4 \mathrm{~K}(-0.9$ to $-1.9 \mathrm{~K})$ at the $\mathrm{LGM}$ and $+0.3 \mathrm{~K}(0.0$ to $+0.5 \mathrm{~K})$ at MIS 5.5 .

\subsubsection{Sea ice}

The glacial increase in annual mean sea ice area between present (Cavalieri and Parkinson, 2008; Parkinson and Cavalieri, 2008) and the LGM (CLIMAP, 1976; Sarnthein et al., 2003; Gersonde et al., 2005) is with $17.5 \times 10^{12} \mathrm{~m}^{2}$ of similar size than the areal coverage of $17 \times 10^{12} \mathrm{~m}^{2}$ of the North American and Eurasian ice sheets. Note that the seasonal cycle of sea ice area at present day is very symmetric (Cavalieri and Parkinson, 2008; Parkinson and Cavalieri, 2008) and therefore the use of the annual mean area together with annual mean local insolation for the estimate in our radiative budget should be only little affected by seasonality. More than $75 \%$ of this increase in sea ice area occurred in the Southern Ocean (8.5 to $22 \times 10^{12} \mathrm{~m}^{2}$ from the present to the LGM), and only little in the north (10 to $14 \times 10^{12} \mathrm{~m}^{2}$ from the present and the LGM). The annual mean insolation over the sea ice latitudes is also larger in the south $\left(250 \mathrm{~W} \mathrm{~m}^{-2}\right.$ in $\left.50-70^{\circ} \mathrm{S}\right)$ than in the north $\left(217 \mathrm{~W} \mathrm{~m}^{-2}\right.$ in $\left.60-90^{\circ} \mathrm{N}\right)$ as these areas are located at lower latitudes (Fig. 4A). These latitudinal bands cover 9 and $7 \%$ of Earth's surface, respectively.

Complete time series of sea ice coverage of the last $800 \mathrm{kyr}$ are not available. We therefore have to relate other relevant time series with estimated glacial/interglacial changes in sea ice area. The temporal variations of sea ice in the Southern Ocean can again be estimated from ice core measurements. It was argued that the sea salt sodium (Na) flux to EPICA Dome $\mathrm{C}$ in Antarctica can be used as proxy for sea ice production in the Indian Ocean sector of Antarctica (Wolff et al., 2003, 2006). However, this proxy becomes less sensitive during full glacial periods because the sea salt source moves northwards due to the expanding sea ice and thus enhanced losses during transport are expected (Fischer et al., 2007a). The EPICA Dome C temperature estimate $\Delta T_{\text {EPICA }}$ (Jouzel et al., 2007) and the logarithm of the sea salt Na flux in EPICA Dome $\mathrm{C}$ are linearly related during transitions and interglacials, but have a different relationship at full glacial conditions, reflecting this transport effect (Röthlisberger et al., 2008). We therefore use for the calculation of $\Delta R_{\text {sea ice } \mathrm{SH}}$ over the last $800 \mathrm{kyr}$ the Antarctic temperature anomaly as reflected by $\Delta T_{\mathrm{EPICA}}$. It is a first order approximation for Southern Ocean sea ice extent as used previously (Köhler and Fischer, 2006). Recently, it was shown that $\Delta T_{\mathrm{EPICA}}$ is highly correlated with SST reconstructions at $40^{\circ} \mathrm{S}$ in the Atlantic section of the Southern Ocean (Martínez-Garcia et al., 2009). For the variability in the north and to calculate $\Delta R_{\text {sea ice NH }}$ we take the model-based temperature anomaly over the northern hemispheric land area (Bintanja et al., 2005), although the latitudinal band of this study is with $40-80^{\circ} \mathrm{N}$ slightly different. We assume a relatively large uncertainty of $\pm 20 \%$ of the areas due to the high uncertainty in sea ice coverage and the weakness of the time series used as sea ice proxy (Fig. 4B). Albedo over sea ice $\alpha_{S I}$ is assumed to be $0.55( \pm 0.1)$, thus $0.45(0.35-0.55)$ larger than over open ocean (Fig. 4C).

Combining this information, the sea ice in the south contributes at the LGM to a reduction in the radiative balance of $-1.7 \mathrm{~W} \mathrm{~m}^{-2}$, while the north accounts for $-0.4 \mathrm{~W} \mathrm{~m}^{-2}$ (Fig. 4D). During warm interglacials only a contribution from the south (e.g. up to $+0.7 \mathrm{~W} \mathrm{~m}^{-2}$ in MIS 5.5) is seen in our estimate. The lack of a contribution from the north for the warm interglacials is caused by the use of the LR0 $4 \delta^{18} \mathrm{O}$ to derive northern high latitude temperature estimates. LR04 shows only limited reductions in $\delta^{18} \mathrm{O}$ during these warm interglacials, thus all climate variables derived by Bintanja et al. (2005) from LR04 contain only small variations during these times. The uncertainty ranges during glacial times are especially for the Southern Ocean rather large (for LGM $1 \sigma= \pm 0.5 \mathrm{~W} \mathrm{~m}^{-2}$ in the south; $1 \sigma= \pm 0.1 \mathrm{~W} \mathrm{~m}^{-2}$ in the north). Altogether the global sea ice area at the LGM leads to $\Delta R_{\text {sea ice }}=-2.1 \mathrm{~W} \mathrm{~m}^{-2}$ with an uncertainty of $0.5-0.6 \mathrm{~W} \mathrm{~m}^{-2}$, which is equivalent to a direct global cooling in $\Delta T_{E, P}$ of $0.7 \mathrm{~K}(-0.5$ to $-0.9 \mathrm{~K})$. 


\subsubsection{Vegetation}

Temporal changes of surface albedo over vegetated land is difficult to prescribe for the past. Available pollen based reconstructions of vegetation distribution are restricted to the northern latitudes for the time period from the LGM to the present and sparse data over Africa for a few time slices, while little is known on changes in South America and South-East Asia (e.g. Prentice et al., 2000; Bigelow et al., 2003; Tarasov et al., 2007). These data show that at the LGM the woody vegetation in the high northern latitudes (boreal and temperate forest) was largely reduced. This is in line with modelling results. Crucifix and Hewitt (2005) identified that especially shifts in the vegetation cover in Siberia (from forest today to grassland at the LGM) and in Tibet (from grassland today to bare soil at the LGM) are responsible for the change in albedo over vegetation and the global response in the radiative forcing of about $-1.4 \mathrm{~W} \mathrm{~m}^{-2}$ at the LGM. Changes in vegetation are spatially very heterogeneous. A simulation study with a dynamic global vegetation model finds also a reduction in tree cover at the LGM of more than $10 \%$ over large parts of the subtropical and tropical regions, however this is balanced by an increase of forested areas elsewhere (Joos et al., 2004). Based on the identification of regions in which vegetation distribution and albedo changes are most important (Bigelow et al., 2003; Crucifix and Hewitt, 2005; Tarasov et al., 2007), we assume an increase in albedo over ice-free land in the latitudinal band $40-80^{\circ} \mathrm{N}$ during colder climates. Changes in albedo are calculated from the temperature anomaly over this area (Bintanja et al., 2005) with a LGM amplitude of $\Delta \alpha_{V}=0.1 \pm 0.05$ (Fig. 5B).

With these assumptions we calculate a reduction in $\Delta R_{\mathrm{veg}}$ of $1.1 \pm 0.6 \mathrm{~W} \mathrm{~m}^{-2}$ at the LGM if only changes in the distribution of vegetation in the high northern latitudes are considered (Fig. 5C). The temperature anomaly in $\Delta T_{E, P}$ at the LGM is $-0.3 \pm 0.2 \mathrm{~K}$. However, we are aware of the spatial heterogeneity of vegetation distribution and that changes south of $40^{\circ} \mathrm{N}$ might need further consideration. This approach considers albedo changes on ice-free land in $40-80^{\circ} \mathrm{N}$. A potential overlap of $\Delta R_{\mathrm{veg}}$ with the albedo forcing of exposed shelves and with the snow albedo forcing on ice-free land in the same latitudes is small and lies within the assumed uncertainty range.

\subsection{Atmospheric albedo-Aerosols as represented by mineral dust}

Aerosols in the climate system are responsible for various effects. They scatter and reflect incoming radiation (direct or albedo effect) and they alter the physics of clouds (indirect effects). The physical understanding of the impact of aerosols (including dust) on climate for present day is very low ( $\mathrm{Ra}$ manathan et al., 2001; Menon et al., 2002; Anderson et al., 2003; Bellouin et al., 2005; Forster et al., 2007; Kiehl, 2007). This lack of knowledge imposes also large uncertainties in the interpretation of dust for past climates (Claquin et al., 2003; Tegen, 2003; Schneider von Deimling et al., 2006a; Fischer et al., 2007b). Here, we focus only on the direct effect of aerosols and base our estimates on observations and modelling results concentrating on mineral dust in the atmosphere. We are aware that this view does not cover all effects which might need consideration, but our understanding of these additional effects is still incomplete and for paleo applications too limited to come to quantitative conclusions.

Models and data compilations indicate that the LGM global averaged mineral dust loading in the atmosphere was significantly larger (about 50\% according to the models) than in preindustrial times (Kohfeld and Harrison, 2001; Mahowald et al., 2006a,b). Mineral dust loadings are spatially very heterogenous and recent models have still difficulties in simulating the observed spatial patterns. For example, core top sediment data find an east to west increase in dust fluxes in the equatorial $\mathrm{Pa}-$ cific but models simulate no changes or even a decrease (Winckler et al., 2008). Furthermore, the dust forcing (similar to the atmospheric dust loading) is itself heterogeneous. Schneider von Deimling et al. (2006a) calculated, for example, a global dust forcing at the LGM of $-1.2 \mathrm{~W} \mathrm{~m}^{-2}$, but because of the heterogeneity a contribution of $-2.1 \mathrm{~W} \mathrm{~m}^{-2}$ in the tropics. A recent study (Chylek and Lohmann, 2008a) estimates an aerosol radiation forcing during the LGM to Holocene transition of $3.3 \pm 0.8 \mathrm{~W} \mathrm{~m}^{-2}$ based on variations in temperature, $\mathrm{CO}_{2}$ and dust in two specific time windows of the Vostok ice core. These conclusions are highly debated (Chylek and Lohmann, 2008b; Ganopolski and Schneider von Deimling, 2008; Hansen et al., 2008; Hargreaves and Annan, 2009), which illustrates that a common understanding is so far missing.

The sources for dust found in EPICA Dome $\mathrm{C}$ are restricted to the Southern Hemisphere, and are probably located in South America during glacials with an Australian contribution during interglacials (Delmonte et al., 2004, 2008; Revel-Rolland et al., 2006). Recently, it has been shown (Winckler et al., 2008), that dust deposits in the equatorial Pacific are highly correlated with dust in Antarctic ice cores. This suggests that dust generation in interhemispheric source regions exhibited a common response to climate change over late-Pleistocene glacial cycles and supports our simple approach used in the following, which relies on these dust measurements in the EPICA Dome $\mathrm{C}$ ice core.

Because of the very low snow accumulation rates at EPICA Dome $\mathrm{C}$, the dominant process for aerosol deposition is dry deposition (Legrand, 1987). Therefore, the flux rather than the concentrations of an aerosol species measured in an ice core is expected to be a measure for its atmospheric concentration (Fischer et al., 2007b). We therefore take the dust flux measured in EPICA Dome C as a first order approximation for temporal variability in global atmospheric dust content (Lambert et al., 2008). The Antarctic dust flux measured in EPICA Dome $\mathrm{C}$ varies by a factor of 40 from $0.5 \mathrm{mg} \mathrm{m}^{-2} \mathrm{yr}^{-1}$ during interglacials to the highest peaks of $20 \mathrm{mg} \mathrm{m}^{-2} \mathrm{yr}^{-1}$ in glacial maxima (Fig. 6B). Variations elsewhere are much smaller, e.g. dust fluxes in the equatorial Pacific vary between 0.1 and $0.4 \mathrm{~g} \mathrm{~m}^{-2} \mathrm{yr}^{-1}$ (Winckler et al., 2008). To reduce the importance of the very high variability in Antarctic dust we use the logarithmic dust flux at EPICA Dome $\mathrm{C}$ and scale it to atmospheric albedo anomalies $\Delta \alpha_{A}$ to derive variations in $\Delta R_{\text {dust }}$ obtained with more complex models cited above. Thus, $\Delta \alpha_{A}$ is not based on underlying physics. It is assumed here to increase at the LGM by $0.006 \pm 0.003$ (Fig. 6B). To calculate the global impact of the dust-albedo forcing we assume no latitudinal dependency of the dust distribution in the atmosphere and calculate anomalies in $\Delta R$ with the global mean insolation (Fig. 6A).

The radiative forcing of dust $\Delta R_{\text {dust }}$ calculated here is $-1.9 \pm$ 
$0.9 \mathrm{~W} \mathrm{~m}^{-2}$ at the LGM (Fig. 6C). The effect of dust on $\Delta T_{E, P}$ is about $-0.6 \mathrm{~K}(-0.3$ to $-0.9 \mathrm{~K})$ during peak glacial times. During interglacials warmer than the Holocene, reduced dust contents in the EPICA ice core record result in a positive dust radiative forcing reaching about $+0.6 \mathrm{~W} \mathrm{~m}^{-2}$. Equatorial $\mathrm{Pa}$ cific dust records (Winckler et al., 2008) also suggest significantly reduced dust fluxes during MIS 11 and MIS $9(-30 \%$ and $-15 \%$ compared to the Holocene inputs, respectively).

\subsection{Combining all processes and considering the feedbacks of water vapour, lapse rate, and clouds}

We can now calculate anomalies in the total radiative forcing by using our best guess estimates and their uncertainties of the forcings discussed above together with additional considerations of the feedbacks. The individual contributions of the forcing processes are compiled in Fig. 7. The total explained radiative forcing $\Delta R_{\text {subtotal }}$ without the additional feedbacks of water vapour, lapse rate and clouds varies during most glacial maxima between -10 and $-13 \mathrm{~W} \mathrm{~m}^{-2}$ (at the LGM: $-12.4 \pm$ 1.2 or $\pm 2.5 \mathrm{~W} \mathrm{~m}^{-2}$, lower or upper estimated uncertainty, respectively) (Fig. 8). At the LGM the combined radiative forcing from surface albedo changes from land ice sheets $(-3.2 \pm$ $\left.0.6 \mathrm{~W} \mathrm{~m}^{-2}\right)$, sea level $\left(-0.6 \pm 0.3 \mathrm{~W} \mathrm{~m}^{-2}\right)$, and vegetation changes $\left(-1.1 \pm 0.6 \mathrm{~W} \mathrm{~m}^{-2}\right)$ add up to $-4.8 \pm 1.5 \mathrm{~W} \mathrm{~m}^{-2}$ which is slightly larger than, e.g. the $-4 \mathrm{~W} \mathrm{~m}^{-2}$ given by Crucifix (2006). Our best guess which combines all radiative forcings with the Planck feedback explains at the LGM a glacial cooling in $\Delta T_{E, P}$ of $-3.9 \pm 0.8 \mathrm{~K}$ (upper estimated uncertainty). In the interglacials warmer than the Holocene $\Delta R_{\text {subtotal }}$ is less than $+1.3 \mathrm{~W} \mathrm{~m}^{-2}$. Only a small temperature rise of less than $0.5 \mathrm{~K}$ can be explained here (Fig. 8).

What do we know about the additional feedbacks of water vapour, lapse rate and clouds neglected so far? Variations in the cloud coverage might be important, but uncertainties for paleoclimates are high. The strength of these feedbacks might be in a first guess estimated from recent observations and modelbased studies (Bony et al., 2006; Soden and Held, 2006; Soden et al., 2008; Andrews and Forster, 2008; Dufresne and Bony, 2008). Please note that different methods to calculate these feedbacks were developed in the past, e.g. the so-called partial radiative perturbation method (Soden et al., 2004). Others tried to approximate them to reduce computational efforts (e.g. Yokohata et al., 2005; Taylor et al., 2007). It furthermore appeared that which method works best is model dependent. The global feedback strength of water vapour $\lambda_{W V}$ was observed recently to be about $2 \mathrm{~W} \mathrm{~m}^{-2} \mathrm{~K}^{-1}$ (Dessler et al., 2008). This roughly fits within the suggested range of state-of-the-art general circulation models which estimated $\lambda_{W V}=1.80 \pm 0.18$ (the values of all feedback parameters and their uncertainties (one standard deviation) are taken from Dufresne and Bony, 2008). The lapse rate feedback and the water vapour feedbacks are related to each other. A combination of both leads to a feedback strength of $\lambda_{W V+L R}=0.96 \pm 0.11 \mathrm{~W} \mathrm{~m}^{-2} \mathrm{~K}^{-1}$. The feedback from clouds is most uncertain and estimated to $\lambda_{C}=0.69 \pm 0.38 \mathrm{~W} \mathrm{~m}^{-2} \mathrm{~K}^{-1}$. The combined overall feedback strength from water vapour, lapse rate and clouds $\lambda_{\text {else }}$ is $1.65 \pm 0.49 \mathrm{~W} \mathrm{~m}^{-2} \mathrm{~K}^{-1}$. If we calculate an equilibrium temperature $\Delta T_{E, \infty}$ after Eqs. 1 and 2 and use $\lambda_{\text {else }}$ of the additional feedbacks the LGM cooling would approximately double to a value of $-8.0 \mathrm{~K}(-6.4 \mathrm{~K}$ to $-9.6 \mathrm{~K}$, upper estimated uncertainty).

The additional feedback strength combined in $\lambda_{\text {else }}$ is calculated with state-of-the-art climate models for future climate warming induced by $2 \times \mathrm{CO}_{2}$. However, studies have shown that the climate sensitivity and thus the feedback strength for the LGM and for $2 \times \mathrm{CO}_{2}$ scenarios differ (Crucifix, 2006; Hargreaves et al., 2007). In three out of four investigated general circulation models the feedback parameter was $0.15-0.65 \mathrm{~W} \mathrm{~m}^{-2} \mathrm{~K}^{-1}$ larger for the LGM than for the $2 \times \mathrm{CO}_{2}$ climate, implying smaller climate sensitivities at the LGM than for the future. Further evidences for a dependency of the cloud feedback on climate comes from the semi-direct effect of the $\mathrm{CO}_{2}$ cloud coupling (Andrews and Forster, 2008). This suggests that we overestimate the equilibrium temperature anomalies $\Delta T_{E, \infty}$ for colder climates for a given feedback strength $\lambda$ (according to Eq. 1), if the latter is parameterised by future warming scenarios. In the light of the existing uncertainty in the feedback strength for different climates a more precise calculation of $\Delta T_{E, \infty}$ including all feedbacks is not possible. An alternative way to use the estimated forcing to constrain climate sensitivity is given in section 4.3.

\section{Discussions and Conclusions}

\subsection{General conclusions}

We want to quantify how much different processes contribute to the changes in past variations in SAT. As global SAT cannot be measured directly our approach can only be compared with proxy-based reconstructions of temperature, combinations of records and modelling results. Antarctic temperature variation $\Delta T_{\mathrm{EPICA}}$ as reconstructed from $\delta \mathrm{D}$ in the EPICA Dome C ice core (Jouzel et al., 2007) has a glacial/interglacial amplitude (LGM to preindustrial times) of $9 \mathrm{~K}$ and shows temperatures up to $4 \mathrm{~K}$ higher than in the Holocene during the previous four interglacials in MIS 5.5, 7.5, 9.3 and 11.3. A comparison of $\Delta T_{\text {EPICA }}$ with Southern Ocean SST has shown that these higher than Holocene temperatures, especially during MIS 5.5 and 9.3, were not restricted to the East Antarctic plateau, but were extending also over parts of the Southern Ocean (Martínez-Garcia et al., 2009). From model-model comparisons it has been derived that polar amplification leads to temperature anomalies in Antarctica which are at the LGM about a factor of two larger than the global mean (MassonDelmotte et al., 2006, 2009). Using this amplification a hypothetical SAT calculated from Antarctic ice cores as $0.5 \times$ $\Delta T_{\mathrm{EPICA}}$ still varies between $-4.5 \mathrm{~K}$ and $+2 \mathrm{~K}$ throughout the last $800 \mathrm{kyr}$ (Fig. 8). In this respect one has to bear in mind, that the polar amplification factor is probably not constant in time, e.g. it is estimated to be smaller in scenarios for future climate change (Masson-Delmotte et al., 2006). Uncertainties in the interpretation of $\Delta T_{\text {EPICA }}$ especially during warmer than Holocene interglacials and the link to global temperature are discussed in Masson-Delmotte et al. (2009).

The $\Delta T$ estimated from EPICA in combination with a polar amplification is considerably larger than the deep ocean temperature variability $\Delta T_{\text {ocean }}$ (Fig. 8), which was deconvoluted from the benthic $\delta^{18} \mathrm{O}$ stack LR04 (Bintanja et al., 2005; Lisiecki and Raymo, 2005). The glacial/interglacial amplitude in $\Delta T_{\text {ocean }}$ 
is of the order of $3 \mathrm{~K}$, which agrees reasonably well with an estimate for mean ocean temperature change over Termination I $(2.7 \pm 0.6 \mathrm{~K})$ based on the $\mathrm{Kr} / \mathrm{N}_{2}$ ratio in a Greenland ice core (Headly and Severinghaus, 2007). A further ocean cooling at glacial times was probably not possible because bottom water masses were close to freezing point in much of the deep ocean (Chappell and Shackleton, 1986; Cutler et al., 2003; Adkins et al., 2002; Waelbroeck et al., 2002). Another remarkable difference between deep ocean temperature anomaly $\left(\Delta T_{\text {ocean }}\right)$ and the SAT based on EPICA is the pronounced warming during the previous four interglacials. They are remarkably smaller (MIS 5.5, 11.3) or non-existing (MIS 7.5, 9.3) in the LR04based deep ocean temperature (Fig. 8).

In the Paleoclimate Modelling Intercomparison Project 2 (PMIP2) the LGM was simulated with coupled ocean-atmosphere general circulation models to be globally $-4.6 \pm 0.9 \mathrm{~K}$ cooler than the preindustrial climate (Masson-Delmotte et al., 2006, 2009; Braconnot et al., 2007a). Schneider von Deimling et al. (2006b) combined an ensemble of coupled climate model simulations with empirical constraints on regional cooling inferred from proxy data and proposes a cooling of global temperature at the LGM of $5.8 \pm 1.4 \mathrm{~K}$. They explain their discrepancy to the PMIP2 results with different assumptions about dust and vegetation forcing. We have to regard the knowledge of reconstructed temperature anomaly as rather uncertain, which becomes apparent in the discrepancy of recent studies and the relatively large uncertainties within single studies and between different models.

This study attempts to explain past temperature variations in terms of perturbations in Earth's radiative budget. Our assumptions are, whenever possible, supported by paleo reconstructions. We can identify the changes in the radiative budget caused by individual processes. From simple principles we calculate the equilibrium temperature anomaly connected with every change in the radiative budget considering only the Planck feedback. We furthermore attach to all our assumptions uncertainty estimates and come up with both a best guess results and a potential range of variability. The temperature decline suggested by our approach for the LGM is without the feedbacks of water vapour, lapse rate and clouds $-3.1 \mathrm{~K}$ to $-4.7 \mathrm{~K}$. If we assume that the strength of these additional feedbacks is independent from climate and can be derived from $2 \times \mathrm{CO}_{2}$ experiments in climate models, then a much larger temperature range of $-6.4 \mathrm{~K}$ to $-9.6 \mathrm{~K}$ for the LGM is suggested. This range exceeds other temperature estimates but its lower end is consistent with reconstructed LGM temperatures (e.g. Farrera et al., 1999; Ballantyne et al., 2005; Schneider von Deimling et al., 2006b; Masson-Delmotte et al., 2009). We like to emphasise the tentative nature of the feedbacks combined in $\lambda_{\text {else. }}$ Feedbacks depend on the climate state (Crucifix, 2006; Hargreaves et al., 2007) which would then according to Eq. 1 explain a smaller temperature anomaly for a larger $\lambda_{\text {else }}$ during glacial climates for the given perturbation in the radiation budget.

To summarise, our compiled range of temperature change for the LGM is with (without) the additional feedbacks of $\lambda_{\text {else }}$ (water vapour, lapse rate, clouds) larger (smaller) than other independent estimates of LGM temperature, although there exists small overlaps in the uncertainty ranges. This strongly suggests that $\lambda_{\text {else }}$ for the LGM was smaller than for present day climate.
An alternative explanation is, that the overall effects might become significantly smaller, if interactions between the individual processes are considered. It might be that the estimates of forcing presented here are on the high side, such that the lower end of our forcing uncertainty range is consistent with other studies even if the additional feedbacks in $\lambda_{\text {else }}$ are accounted for with present day strength.

\subsection{Unaccounted effects}

Besides the changes in the radiative budget discussed so far, the expanded continental ice sheets influenced and maintained the LGM climate not only through their albedo but also through their height. The atmosphere is mainly heated from below (Peixoto and Oort, 1992), and therefore the signal of lowered temperatures at the sea surface will be transported to higher elevations over land, producing a colder climate over the continents, especially over the area of the Laurentide Ice Sheet. These lowered temperatures again affect the large-scale distribution of temperature, e.g. in the North Atlantic region and further downstream. In several model experiments, Romanova et al. (2006) found that the changes of the orography and albedo caused by the Laurentide Ice Sheet induce strong temperature changes of about $\sim 16 \mathrm{~K}$ north of $30^{\circ} \mathrm{N}$, and much smaller changes elsewhere (Figure 5b in Romanova et al., 2006). Since these temperature changes are found to be non-linearly related to the ice sheet height and sea level, it is difficult to provide a global estimate of these temperature changes and we only consider them to be an additional unaccounted uncertainty.

A component of the Earth's climate not considered at all, but which might be potentially of relevance is volcanism. Volcanic emissions are known to have a non-negligible impact on Earth's radiative budget. The aerosols introduced into the atmosphere by volcanism lead to global cooling, which is of the order of less than $1 \mathrm{~W} \mathrm{~m}^{-2}$ to some $\mathrm{W} \mathrm{m}^{-2}$, depending on the size of eruption (e.g. Soden et al., 2002; Joos and Spahni, 2008). These are impacts which last only a couple of years to a decade and do not lead to long-lasting changes. However, in a recent study it was concluded that multiple volcanic eruptions might have been partly responsible for the long-term cooling during the $13^{\text {th }}$ century from the Medieval Warm Period to the Little Ice Age (Schneider et al., 2009). Due to the largely unknown history of volcanic activity its importance during the past $800 \mathrm{kyr}$ is difficult to assess. There is generally no correlation of volcanic events recorded in the EPICA Dome $\mathrm{C}$ ice cores with climate during the past $45 \mathrm{kyr}$ (Castellano et al., 2004). However, it was suggested (Bryson et al., 2006; Huybers and Langmuir, 2009) that volcanic activity increases during deglaciation as a consequence of the increase in magma production in response to deglacial decompression of the mantle. This would imply less volcanic activity during glacial periods with a smaller cooling effect from aerosol leading to higher glacial temperature. This idea would therefore reduce suggested temperature changes during glacials and would bring results from our approach in better agreement with other studies.

\subsection{Constraints on climate sensitivity from the LGM}

An alternative approach to the LGM temperature estimate above is to estimate climate sensitivity from the calculated LGM 
radiative forcing and global LGM cooling. While such calculations have been performed before (Hoffert and Covey, 1992; Lorius et al., 1990; Covey et al., 1996; Genthon et al., 1987; Hansen et al., 1993; Annan and Hargreaves, 2006; Hansen et al., 2008; Edwards et al., 2007; Chylek and Lohmann, 2008a; Ganopolski and Schneider von Deimling, 2008), many have not carefully considered all forcings and all uncertainties and most if not all have not considered the possibility of the climate sensitivity being state dependent. In order to be relevant for the present anthropogenic warming, we need to estimate, what is called the 'Charney' sensitivity (Charney et al., 1979), i.e. the equilibrium global warming that would result from a doubling of preindustrial atmospheric $\mathrm{CO}_{2}$ from the Planck feedback, the lapse rate, water vapour, sea ice and snow albedo and the cloud feedback, but excluding the feedbacks associated with changes in ice sheets and the distribution of vegetation (see Knutti and Hegerl, 2008, for a discussion of the concepts). This is the sensitivity that the current climate models calculate and it is the quantity that is the largest source of uncertainty to predict warming for the next few centuries (Knutti et al., 2002, 2008). The Charney sensitivity is in most cases identical to $\Delta T_{2 \times \mathrm{CO}_{2}}$, although some models nowadays also consider in their calculation of $\Delta T_{2 \times \mathrm{CO}_{2}}$ variations in vegetation or ice sheets. It would be interesting to perform this kind of analysis for a lot of different climate states, e.g. over the whole $800 \mathrm{kyr}$ period, however its usefulness depends on the uncertainty of the reconstructed global temperature change. This uncertainty is still too large for most periods, and we therefore restrict this application to the LGM, for which temperature was reconstructed from both data and models with sufficient accuracy.

The total forcing for the LGM period (23-19 kyr BP) from this analysis is $-9.5 \mathrm{~W} \mathrm{~m}^{-2}$, which is the sum of all forcing components except the snow and sea ice albedo forcing $\left(-3.0 \mathrm{~W} \mathrm{~m}^{-2}\right)$ which is considered as a feedback when calculating the Charney sensitivity. We assume a normal distribution centred at $-9.5 \mathrm{~W} \mathrm{~m}^{-2}$ and a standard deviation between $0.9 \mathrm{~W} \mathrm{~m}^{-2}$ (lower estimate) and $1.9 \mathrm{~W} \mathrm{~m}^{-2}$ (upper estimate) to describe the probability distribution of the forcing, shown in Fig. 9B. We furthermore take the results of Schneider von Deimling et al. (2006b) to quantify the LGM cooling of $5.8 \pm 1.4 \mathrm{~K}$ (Fig. 9A). It is difficult to obtain an LGM cooling from observations only, as the scaling of regional proxy data (e.g. from tropical sea surface temperature or polar ice cores) often involves model based information (e.g. MassonDelmotte et al., 2009). However, the range obtained by Schneider von Deimling et al. (2006b) is consistent with data from different proxy archives (e.g. Farrera et al., 1999; Ballantyne et al., 2005).

The ratio between LGM cooling and radiative forcing leads to a distribution for climate sensitivity. However, additional uncertainties need to be considered. A recent study (Hargreaves et al., 2007) with a general circulation model indicates that the LGM sensitivity to $\mathrm{CO}_{2}$ is likely to be smaller than the sensitivity of the current climate state, although the model spread is large (i.e. in some model versions the LGM sensitivity was smaller and in some versions it was found to be larger). The results by Hargreaves et al. (2007) indicate that the LGM sensitivity is on average about $15 \%$ smaller than for $2 \times \mathrm{CO}_{2}$ climate (see their Fig. 5), and we therefore use a best guess of 0.85 and a standard deviation of 0.2 for the scaling factor. Other climate models confirm that the feedbacks are likely to be different at the LGM (Crucifix, 2006; Otto-Bliesner et al., 2009). An additional factor is the efficacy of the forcing, the fact that the sen- sitivity depends on the type of the forcing (Hansen et al., 2005; Davin et al., 2007), and to some extent also on the magnitude of the forcing (Boer et al., 2005; Colman and McAvaney, 2009). All of these effects are poorly understood, but we try to account for these by the scaling factor (Fig. 9C). The standard deviation is chosen somewhat wider than the results by Hargreaves et al. (2007) indicate, in order to account for the uncertainty in the efficacy of non- $\mathrm{CO}_{2}$ forcings.

The ratio between temperature and radiative forcing divided by the scaling factor leads to the probability distribution of climate sensitivity for $2 \times \mathrm{CO}_{2}$ estimated from the LGM data (assuming a radiative forcing of $3.71 \mathrm{~W} \mathrm{~m}^{-2}$ for the $\mathrm{CO}_{2}$ doubling only (Myhre et al., 1998)) (Fig. 9D). The distribution reveals several features that do not strongly depend on the details of the assumed input distributions. First, the estimated best guess and uncertainty for climate sensitivity based on the LGM is consistent with earlier LGM work (Lorius et al., 1990; Hansen et al., 1993; Covey et al., 1996), new studies based on perturbed physics ensembles (Annan et al., 2005; Schneider von Deimling et al., 2006a) as well as the range derived by the PMIP2 models (Otto-Bliesner et al., 2009). Climate sensitivity in our analysis is very likely in the range $1.4-5.2 \mathrm{~K}(5-95 \%)$, the most likely value is $2.4 \mathrm{~K}$, well within the consensus range of $2-4.5 \mathrm{~K}$ based on multiple lines of evidence (Solomon et al., 2007; Knutti and Hegerl, 2008). Second, the uncertainties are large if all forcings and uncertainties are considered properly, and the LGM does not provide a strong constraint on sensitivity. Low values of climate sensitivities (i.e. almost no net feedbacks, $\lambda_{\text {else }}$ close to zero) are unlikely but possible. However, in contrast to the results by Chylek and Lohmann (2008a), our analysis shows that medium values around $2-3 \mathrm{~K}$ are more likely and high values also cannot be excluded (see also Ganopolski and Schneider von Deimling, 2008; Hargreaves and Annan, 2009). Third, the likelihood for high climate sensitivity values derived here is lower than in other studies based on climate models (Piani et al., 2005; Stainforth et al., 2005; Knutti et al., 2006) or the observed $20^{\text {th }}$ century warming (e.g. Knutti et al., 2002; Forest et al., 2002). Values above $6 \mathrm{~K}$ are not supported by this analysis, but the plausible range still exceeds the range covered by general circulation models $(2.1-4.4 \mathrm{~K})$ (Solomon et al., 2007). These conclusions however are subject to several assumptions including the efficacy of forcing and how feedbacks at the LGM relate to present. We try to roughly account for these by the uncertain scaling factor but the scientific understanding of these effects is low and uncertainties may be even larger than what is considered here. Fourth, the distribution of climate sensitivity is skewed towards high values, similar to other methods, because the uncertainty in the denominator of the ratio is large. This is rather fundamental and unlikely to disappear soon, as a better constraint on the forcing will be difficult to obtain (but see discussion on climate sensitivity in Roe and Baker, 2007; Baker and Roe, 2009; Hannart et al., 2009; Tanaka et al., 2009). 


\subsection{Limitations and summary}

In its global and annual mean view our approach has certainly its limitations. Especially spatially highly heterogenous processes such as cloud cover, mineral dust loading in the atmosphere, and vegetation-albedo forcing can only be roughly estimated and seasonal variability can not be addressed at all (Braconnot et al., 2007b). The state dependence of feedbacks is poorly understood (Hargreaves et al., 2007) and the problem of efficacy of different forcings (e.g. Hansen et al., 2005) is neglected. The concept of radiative forcing is limited in particular for spatially heterogeneous forcings and surface forcings (Davin et al., 2007). We nevertheless believe, that by concentrating on these global impacts we can distinguish the importance of different processes and especially focus on their temporal variability. We like to emphasise again, that our view is based on what we know from paleo reconstructions and we use models only when necessary. With this approach we compile a radiative forcing at the $\mathrm{LGM}$ of $-12.4 \mathrm{~W} \mathrm{~m}^{-2}$ with an uncertainty of \pm 1.2 to $\pm 2.5 \mathrm{~W} \mathrm{~m}^{-2}$, which comprises the greenhouse effect from $\mathrm{CO}_{2}, \mathrm{CH}_{4}$, and $\mathrm{N}_{2} \mathrm{O}\left(-2.8 \mathrm{~W} \mathrm{~m}^{-2}\right)$, surface albedo changes over land cryosphere $\left(-4.5 \mathrm{~W} \mathrm{~m}^{-2}\right)$, sea ice $\left(-2.1 \mathrm{~W} \mathrm{~m}^{-2}\right)$ and vegetation $\left(-1.1 \mathrm{~W} \mathrm{~m}^{-2}\right)$, and the atmospheric albedo effect caused by atmospheric dust loadings $\left(-1.9 \mathrm{~W} \mathrm{~m}^{-2}\right)$.

Our compilation shows that the response of different components contributing to the radiative balance of the Earth can quantitatively explain a cooling at the LGM of at least 3.1 to $4.7 \mathrm{~K}$ directly from paleo reconstructions or model interpretation of available proxy records considering only the Planck feedback. The feedback processes not considered in detail (water vapour, lapse rate, clouds) would, if taken at present day feedback strength, enlarge the temperature anomaly at the LGM to -6.4 to $-9.6 \mathrm{~K}$. Data and climate model-based results support only the lower end of that temperature range. One possible interpretation of this discrepancy is, that the feedback strength of water vapour, lapse rate, and clouds, (and connected with that climate sensitivity), depends on climate itself. A best estimate and uncertainty for the reconstructed radiative forcing and LGM cooling support an equilibrium or Charney climate sensitivity for $2 \times \mathrm{CO}_{2}$ between 1.4 and $5.2 \mathrm{~K}$, somewhat smaller than other methods but consistent with the consensus range of $2-4.5$ K (Solomon et al., 2007; Knutti and Hegerl, 2008). Relatively high and low values both cannot be excluded. Climate sensitivities above $6 \mathrm{~K}$ are difficult to reconcile with LGM reconstructions, assuming that the concept of a reasonably constant sensitivity is valid for the LGM and current climate. The latter needs further quantification in comprehensive models, but the currently available results indicate that the translation of LGM feedbacks to present is more uncertain than assumed in earlier studies that simply relate a global temperature to a global forcing. For the warmer than Holocene interglacials we lack a quantitative understanding of the radiative changes and corresponding temperature anomalies. This is probably caused by the use of the LR04 benthic $\delta^{18} \mathrm{O}$ stack as source out of which various climate variables were deconvoluted (LR0 $4 \delta^{18} \mathrm{O}$, a proxy for ice volume and global temperature changes, varies only little during warm interglacials). Processes, which can potentially explain parts of these warmings are smaller sea ice cover and less snow cover on land.

\section{Acknowledgements}

This work is a contribution to the European Project for Ice Coring in Antarctica (EPICA), a joint European Science Foundation/European Commission scientific programme, funded by the EU (EPICA-MIS) and by national contributions from Belgium, Denmark, France, Germany, Italy, the Netherlands, Norway, Sweden, Switzerland and the United Kingdom. The main logistic support was provided by IPEV and PNRA (at Dome C) and AWI (at Dronning Maud Land). This is EPICA publication no. 240. We like to thank D. Lüthi and P. Kaufmann for providing data sets prior to publication, and M. Siddall, M. Crucifix, and C. Waelbroeck for in-depth reviews. FJ acknowledges support by the Swiss National Science Foundation and VMD by Agence Nationale de la Recherche (ANR, projects PICC and NEEM).

\section{References}

Adkins, J. F., McIntyre, K., Schrag, D. P., 2002. The salinity, temperature, and $\delta^{18} \mathrm{O}$ of the glacial deep ocean. Science $298,1769-1773$.

Anderson, T. L., Charlson, R. J., Schwartz, S. E., Knutti, R., Boucher, O., Rodhe, H., Heintzenberg, J., 2003. Climate forcing by aerosols - a hazy picture. Science 300, 1103-1104.

Andrews, T., Forster, P. M., 2008. $\mathrm{CO}_{2}$ forcing induces semi-direct effects with consequences for climate feedback interpretations. Geophysical Research Letters 35, L04802, doi: 10.1029/2007GL032273.

Annan, J. D., Hargreaves, J., Ohgaito, R., Abe-Ouchi, A., Emori, S., 2005. Efficiently constraining climate sensitivity with ensembles of paleoclimate simulations. SOLA 1, 181-184, doi: 10.2151/sola.2005-047.

Annan, J. D., Hargreaves, J. C., Mar. 2006. Using multiple observationallybased constraints to estimate climate sensitivity. Geophysical Research Letters 33, L06704, doi: 10.1029/2005GL025259.

Baker, M. B., Roe, G. H., Sep. 2009. The Shape of Things to Come: Why Is Climate Change So Predictable? Journal of Climate 22 (17), 4574-4589, doi: 10.1175/2009JCLI2647.1.

Ballantyne, A. P., Lavine, M., Crowley, T. J., Liu, J., Baker, P. B., 2005. Metaanalysis of tropical surface temperatures during the Last Glacial Maximum. Geophysical Research Letters 32, L05712, doi: 10.1029/2004GL021217.

Bard, E., Raisbeck, G., Yiou, F., Jouzel, J., 2000. Solar irradiance during the last 1200 years based on cosmogenic nuclides. Tellus 52B, 985-992.

Bellouin, N., Boucher, O., Haywood, J., Reddy, M. S., 2005. Global estimate of aerosol direct radiative forcing from satellite measurements. Nature 438, 1138-1141, doi: 10.1038/nature04348.

Berger, A. L., 1978. Long-term variations of daily insolation and Quaternary climatic changes. Journal of Atmospheric Sciences 35, 2362-2367.

Bigelow, N. H., Brubaker, L. B., Edwards, M. E., Harrison, S. P., Prentice, I. C., Anderson, P. M., Andreev, A. A., Bartlein, P. J., Christensen, T. R., Cramer, W., Kaplan, J. O., Lozhkin, A. V., Matveyeva, N. V., Murray, D. F., McGuire, A. D., Razzhivin, V. Y., Ritchie, J. C., Smith, B., Walker, D. A., Gajewski, K., Wolf, V., Holmqvist, B. H., Igarashi, Y., Kremenetskii, K., Paus, A., Pisaric, M. F. J., Volkova, V. S., 2003. Climate change and Arctic ecosystems: 1. Vegetation changes north of $55^{\circ} \mathrm{N}$ between the Last Glacial Maximum, mid-Holocene, and present. Journal of Geophysical Research 108 (D19), 8170, doi: 10.1029/2002JD002558.

Bintanja, R., Oerlemans, J., 1996. The effect of reduced ocean overturning on the climate of the last glacial maximum. Climate Dynamics 12, 523-533.

Bintanja, R., van de Wal, R., Oerlemans, J., 2005. Modelled atmospheric temperatures and global sea levels over the past million years. Nature 437, 125128, doi: 10.1038/nature03975.

Bintanja, R., van de Wal, R. S. W., 2008. North American ice-sheet dynamics and the onset of the 100,000-year glacial cycles. Nature 454, 869-872, doi: 10.1038 /nature07158.

Bintanja, R., van de Wal, R. S. W., Oerlemans, J., 2002. Global ice volume variations through the last glacial cycle simulated by a 3-D ice-dynamics model. Quaternary International 95-96, 11-23.

Blanchon, P., Eisenhauer, A., Fietzke, J., Liebetrau, V., Apr. 2009. Rapid sealevel rise and reef back-stepping at the close of the last interglacial highstand. Nature 458 (7240), 881-884, doi: 10.1038/nature07933. 
Boer, G. J., Hamilton, K., Zhu, W., 2005. Climate sensitivity and climate change under strong forcing. Climate Dynamics 24, 685-700, doi: 10.1007/s00382-0500-3.

Bony, S., Colman, R., Kattsov, V. M., Allan, R. P., Bretherton, C. S., Dufresne, J.-L., Hall, A., Hallegatte, S., Holland, M. M., Ingram, W., Randall, D. A., Soden, B. J., Tselioudis, G., Webb, M. J., 2006. How well do we understand and evaluate climate change feedback processes? Journal of Climate 19, 3445-3482.

Braconnot, P., Otto-Bliesner, B., Harrison, S., Joussaume, S., Peterchmitt, J.-Y., Abe-Ouchi, A., Crucifix, M., Driesschaert, E., Fichefet, T., Hewitt, C. D., Kageyama, M., Kitoh, A., Laîné, A., Loutre, M.-F., Marti, O., Merkel, U., Ramstein, G., Valdes, P., Weber, S. L., Yu, Y., Zhao, Y., 2007a. Results of PMIP2 coupled simulations of the Mid-Holocene and Last Glacial Maximum - Part 1: experiments and large-scale features. Climate of the Past 3 , 261-277.

Braconnot, P., Otto-Bliesner, B., Harrison, S., Joussaume, S., Peterchmitt, J.-Y., Abe-Ouchi, A., Crucifix, M., Driesschaert, E., Fichefet, T., Hewitt, C. D., Kageyama, M., Kitoh, A., Loutre, M.-F., Marti, O., Merkel, U., Ramstein, G., Valdes, P., Weber, S. L., Yu, Y., Zhao, Y., 2007b. Results of PMIP2 coupled simulations of the Mid-Holocene and Last Glacial Maximum - Part 2: feedbacks with emphasis on the location of the ITCZ and mid- and high latitudes heat budget. Climate of the Past 3, 279-296.

Brohan, P., Kennedy, J. J., Harris, I., Tett, S. F. B., Jones, P. D., 2006. Uncertainty estimates in regional and global observed temperature changes: a new data set from 1850. Journal of Geophysical Research 111, D12106, doi: 10.1029/2005JD006548

Bryson, R. U., Bryson, R. A., Ruter, A., 2006. A calibrated radiocarbon database of late Quaternary volcanic eruptions. eEarth Discussions 1, 123 134.

Castellano, E., Becagli, S., Jouzel, J., Migliori, A., Severi, M., Steffensen, J. P., Traversi, R., Udisti, R., 2004. Volcanic eruption frequency over the last $45 \mathrm{kyr}$ as recorded in EPICA Dome $\mathrm{C}$ ice core (East Antarctica) and its relationship with climatic changes. Global and Planetary Change 42, 195 205, doi: 10.1016/j.gloplacha.2003.11.007.

Cavalieri, D. J., Parkinson, C. L., 2008. Antarctic sea ice variability and trends, 1979-2006. Journal of Geophysical Research 113, C07004, doi: 10.1029/2007JC004564

Chappell, J., Shackleton, N. J., Nov. 1986. Oxygen isotopes and sea level. Nature 324 (6093), 137-140, doi: 10.1038/324137a0.

Charney, J. G., Arakawa, A., Baker, D. J., Bolin, B., Dickinson, R. E., Goody, R. M., Leith, C. E., Stommel, H. M., Wunsch, C. I., 1979. Carbon Dioxide and Climate: A Scientific Assessment. National Academy of Science, Washington, D.C.

Chylek, P., Lohmann, U., 2008a. Aerosol radiative forcing and climate sensititvity deduced from the Last Glacial Maximum to Holocene transition. Geophysical Research Letters 35, L04804, doi: 10.1029/2007GL032759.

Chylek, P., Lohmann, U., 2008b. Reply to comment from Andrey Ganopolski and Thomas Schneider von Deimling on Aerosol radiative forcing and climate sensitivity deduced from the Last Glacial Maximum to Holocene transition. Geophysical Research Letters 35, L23704, doi: 10.1029/2008GL034308.

Claquin, T., Roelandt, C., Kohfeld, K. E., Harrison, S. P., Tegen, I., Prentice, I. C., Balkanski, Y., Bergametti, G., Hansson, M., Mahowald, N., Rodhe, H., Schulz, M., 2003. Radiative forcing of climate by ice-age atmospheric dust. Climate Dynamics 20, 193-202, doi: 10.1007/s00382-002-0269-1.

CLIMAP, 1976. The surface of the ice-age Earth. Science 191, 1131-1137.

Colman, R., McAvaney, B., 2009. Climate feedbacks under a very broad range of forcing. Geophysical Research Letters 36, L01702, doi: 10.1029/2008GL036268.

Covey, C., Sloan, L. C., Hoffert, M. I., 1996. Paleoclimate data constraints on climate sensitivity: the paleocalibration method. Climatic Change 32, 165 184

Crucifix, M., 2006. Does the Last Glacial Maximum constrain climate sensitivity? Geophysical Research Letters 33, L18701, doi: 10.1029/2006GL027137.

Crucifix, M., Hewitt, C. D., 2005. Impact of vegetation changes on the dynamics of the atmosphere at the Last Glacial Maximum. Climate Dynamics 25, 447-459, doi: 10.1007/s00382-005-0013-8.

Cuffey, K. M., Marshall, S. J., 2000. Substantial contribution to sea-level rise during the last interglacial from the Greenland ice sheet. Nature 404, 591594, doi: $10.1038 / 35007053$.

Cutler, K., Edwards, R., Taylor, F., Cheng, H., Adkins, J., Gallup, C., Cutler, P., Burr, G., Bloom, A., 2003. Rapid sea-level fall and deep-ocean temperature change since the last interglacial period. Earth and Planetary Science Letters
206 (3-4), 253 - 271, doi: 10.1016/S0012-821X(02)01107-X

Davin, E. L., de Noblet-Ducoudré, N., Friedlingstein, P., 2007. Impact of land cover change on surface climate: Relevance of the radiative forcing. Geophysical Research Letters 34, L13702, doi: 10.1029/2007GL029678.

de Vernal, A., Hillaire-Marcel, C., 2008. Natural variability of Greenland climate, vegetation, and ice volume during the past million years. Science 320 , 1622-1625, doi: 10.1126/science. 1153929 .

Delmonte, B., Andersson, P. S., Hansson, M., Schöberg, H., Petit, J. R., BasileDoelsch, I., Maggi, V., 2008. Aeolian dust in East Antarctica (EPICA-Dome $\mathrm{C}$ and Vostok): Provenance during glacial ages over the last $800 \mathrm{kyr}$. Geophysical Research Letters 35, L07703, doi: 10.1029/2008GL033382.

Delmonte, B., Basile-Doelsch, I., Petit, J.-P., Maggi, V., Revel-Rolland, M., Michard, A., Jagoutz, E., Grousset, F., 2004. Comparing the EPICA and Vostok dust records during the last 220,000 years: stratigraphical correlation and provenance in glacial periods. Earth-Science Reviews 66, 63-87.

Dessler, A. E., Zhang, Z., Yang, P., 2008. Water-vapor climate feedback inferred from climate fluctuations, 2003-2008. Geophysical Research Letters 35, L20704, doi: 10.1029/2008GL035333.

Dufresne, J.-L., Bony, S., 2008. An assessment of the primary sources of spread of global wamring estimates from coupled atmosphere-ocean models. Journal of Climate 21, 5135-5144, doi: 10.1175/2008JCLI2239.1.

Dutton, A., Bard, E., Antonioli, F., Esat, T. M., Lambeck, K., McCulloch, M. T., May 2009. Phasing and amplitude of sea-level and climate change during the penultimate interglacial. Nature Geoscience 2 (5), 355-359, $10.1038 /$ ngeo470.

Edwards, T. L., Crucifix, M., Harrison, S. P., 2007. Using the past to constrain the future: how the paleorecord can improve estimates of global warming. Progress in Physical Geography 31, 481-500, doi: $10.1177 / 0309133307083295$.

Fairbanks, R. G., 1989. A 17,000-year glacio-eustatic sea level record: influence of glacial melting rates on the Younger Dryas event and deep-ocean circulation. Nature 342, 637-642.

Farrera, I., Harrison, S. P., Prentice, I. C., Ramstein, G., Guiot, J., Bartlein, P. J., Bonnefille, R., Bush, M., Cramer, W., von Grafenstein, U., Holmgren, K., Hooghiemstra, H., Hope, G., Jolly, D., Lauritzen, S.-E., Ono, Y., Pinot, S., Stute, M., Yu, G., 1999. Tropical climates at the Last Glacial Maximum: a new synthesis of terrestrial palaeoclimate data. I. Vegetation, lake-levels and geochemistry. Climate Dynamics 15, 823-856.

Fischer, H., Fundel, F., Ruth, U., Twarloh, B., Wegner, A., Udisti, R., Becagli, S., Castellano, E., Morganti, A., Severi, M., Wolff, E. W., Littot, G., Röthlisberger, R., Mulvaney, R., Hutterli, M. A., Kaufmann, P., Federer, U., Lambert, F., Bigler, M., Hansson, M., Jonsell, U., de Angelis, M., Boutron, C., Siggaard-Andersen, M.-L., Steffensen, J. P., Barbante, C., Gaspari, V., Gabrielli, P., Wagenbach, D., 2007a. Reconstruction of millennial changes in dust emission, transport and regional sea ice coverage using the deep EPICA ice cores from the Atlantic and Indian Ocean sector of Antarctica. Earth and Planetary Science Letters 260, 340-354, doi: 10.1016/j.epsl.2007.06.014.

Fischer, H., Siggaard-Andersen, M.-L., Ruth, U., Röthlisberger, R., Wolff, E., 2007b. Glacial/interglacial changes in mineral dust and sea-salt records in polar ice cores: sources, transport, and deposition. Reviews of Geophysics 45, RG1002, doi: 10.1029/RG000192.

Fitzpatrick, M. F., Warren, S. G., 2007. The relative importance of clouds and sea ice for the solar energy budget of the Southern Ocean. Journal of Climate 20,941-954, doi: 10.1175/jcli4040.1.

Flückiger, J., Blunier, T., Stauffer, B., Chappellaz, J., Spahni, R., Kawamura, K., Schwander, J., Stocker, T. F., Dahl-Jensen, D., 2004. $\mathrm{N}_{2} \mathrm{O}$ and $\mathrm{CH}_{4}$ variations during the last glacial epoch: insights into global processes. Global Biogeochemical Cycles 18, GB1020, doi: 10.1029/2003GB002122.

Forest, C. E., Stone, P. H., Sokolov, A. P., Allen, M. R., Webster, M. D., 2002. Quantifying uncertainties in climate system properties with the use of recent climate observations. Science 295, 113-117.

Forster, P., Ramaswamy, V., Artaxo, P., Berntsen, T., Betts, R., Fahey, D., Haywood, J., Lean, J., Lowe, D., Myhre, G., Nganga, J., Prinn, R., Raga, G., Schulz, M., Dorland, R. V., 2007. Changes in Atmospheric Constituents and in Radiative Forcing. In: Solomon, S., Qin, D., Manning, M., Chen, Z., Marquis, M., Averyt, K. B., Tignor, M., Miller, H. L. (Eds.), Climate Change 2007: The Physical Science Basis. Contribution of Working Group I to the Fourth Assessment Report of the Intergovernmental Panel on Climate Change. Cambridge University Press, Cambridge, United Kingdom and New York, NY, USA, pp. 129-234.

Foukal, P., Frohlich, C., Spruit, H., Wigley, T. M. L., Sep. 2006. Variations in solar luminosity and their effect on the Earth's climate. Nature 443 (7108), 161-166, doi: 10.1038/nature05072. 
Friedlingstein, P., Cox, P., Betts, R., Bopp, L., von Bloh, W., Brovkin, V., Cadule, P., Doney, S., Eby, Fung, I., Bala, G., John, J., Joos, F., Kato, T., Kawamiya, M., Knorr, W., Lindsay, K., Matthews, H. D., Raddatz, T., Rayner, P., Reick, C., Roeckner, E., Schnitzler, K.-G., Schnur, R., Strassmann, K., Weaver, A. J., Yoshikawa, C., Zeng, N., 2006. Climate-carbon cycle feedback analysis: results from the $\mathrm{C}^{4} \mathrm{MIP}$ model intercomparison. Journal of Climate 19, 3337-3353, doi: 10.1175/JCLI3800.1.

Fröhlich, C., 2006. Solar irradiance variability since 1978: Revision of the PMOD Composite during Solar Cycle 21. Space Science Reviews 125, $53-$ 65, doi: 10.1007/s11214-006-9046-5.

Ganopolski, A., Schneider von Deimling, T., 2008. Comment on Aerosol radiative forcing and climate sensitivity deduced from the Last Glacial Maximum to Holocene transition by Petr Chylek and Ulrike Lohmann. Geophysical Research Letters 35, L23703, doi: 10.1029/2008GL033888.

Genthon, C., Barnola, J. M., Raynaud, D., Lorius, C., Jouzel, J., Barkov, N. I., Korotkevich, Y. S., Kotlyakov, V. M., 1987. Vostok ice core; climatic response to $\mathrm{CO}_{2}$ and orbital forcing changes over the last climatic cycle. Nature $329,414-418$.

Gersonde, R., Crosta, X., Abelmann, A., Armand, L., 2005. Sea-surface temperature and sea ice distribution of the Southern Ocean at the EPILOG Last Glacial Maximum - a circum-Antarctic view based on siliceous microfossil records. Quaternary Science Reviews 24, 869-896, doi: 10.1016/j.quascirev.2004.07.015.

Goode, P. R., Qiu, J., Yurchyshyn, V., Hickey, J., Chu, M.-C., Kolbe, E., Brown, C. T., Koonin, S. E., 2001. Earthshine observations of the Earth's reflectance. Geophysical Research Letters 28, 1671-1674.

Hannart, A., Dufresne, J.-L., Naveau, P., Aug. 2009. Why climate sensitivity may not be so unpredictable. Geophysical Research Letters 36, L16707, doi: 10.1029/2009GL039640.

Hansen, J., Lacis, A., Rind, D., Russell, G., Stone, P., Fung, I., Ruedy, R., Lerner, J., 1984. Climate sensitivity: Analysis of feedback mechanisms. In: Hansen, J., Takahashi, T. (Eds.), Climate Processes and Climate Sensitivity. Vol. 29 of Geophysical Monographs. American Geophysical Union, Washington, USA, pp. 130-163.

Hansen, J., Lacis, A., Ruedy, R., Sato, M., Wilson, H., 1993. How sensitive is the world's climate? National Geographic Research \& Exploration 9, 142 158

Hansen, J., Sato, M., Kharecha, P., Beerling, D., Berner, R., Masson-Delmotte, V., Pagani, M., Raymo, M., Royer, D. L., Zachos, J. C., 2008. Target atmospheric $\mathrm{CO}_{2}$ : Where should humanity aim? The Open Atmospheric Science Journal 2, 217-231, doi: 10.2174/1874282300802010217.

Hansen, J., Sato, M., Kharecha, P., Russell, G., Lea, D. W., Siddall, M., 2007. Climate change and trace gases. Philosophical Transactions of the Royal Society London A 365, 1925-1954, doi: 10.1098/rsta.2007.2052.

Hansen, J., Sato, M., Ruedy, R., Nazarenko, L., Lacis, A., Schmidt, G. A., Russell, G., Aleinov, I., Bauer, M., Bauer, S., Bell, N., Cairns, B., Canuto, V., Chandler, M., Cheng, Y., Genio, A. D., Faluvegi, G., Fleming, E., Friend, A., Hall, T., Jackman, C., Kelley, M., Kiang, N., Koch, D., Lean, J., Lerner, J., Lo, K., Menon, S., Miller, R., Minnis, P., Novakov, T., Oinas, V., Perlwitz, J., Perlwitz, J., Rind, D., Romanou, A., Shindell, D., Stone, P., Sun, S., Tausnev, N., Thresher, D., Wielicki, B., Wong, T., Yao, M., , Zhang, S., 2005. Efficacy of climate forcings. Journal of Geophysical Research 110, D18104, doi: 10.1029/2005JD005776.

Hargreaves, J. C., Abe-Ouchi, A., Annan, J. D., 2007. Linking glacial and future climates through an ensemble of GCM simulations. Climate of the Past $3,77-87$.

Hargreaves, J. C., Annan, J. D., 2009. Comment on Aerosol radiative forcing and climate sensitivity deduced from the Last Glacial Maximum to Holocene transition, by P. Chylek and U. Lohmann, Geophysical Research Letters, 2008. Climate of the Past 5 (2), 143-145.

Hays, J. D., Imbrie, J., Shackelton, N. J., 1976. Variations in the Earth's Orbit: Pacemaker of the Ice Ages. Science 194, 1121-1132.

Headly, M. A., Severinghaus, J. P., 2007. A method to measure $\mathrm{Kr} / \mathrm{N}_{2}$ ratios in air bubbles trapped in ice cores and its application in reconstructing past mean ocean temperature. Journal of Geophysical Research 112, D19105, doi: 10.1029/2006JD008317.

Hoffert, M. I., Covey, C., 1992. Deriving global climate sensitivity from paleoclimate reconstructions. Nature 360, 573-576.

Huybers, P., Langmuir, C., 2009. Feedback between deglaciation and volcanism, and atmospheric $\mathrm{CO}_{2}$. Earth and Planetary Science Letters, in press, doi: 10.1016/j.eps1.2009.07.014.

Jansen, E., Overpeck, J., Briffa, K., Duplessy, J.-C., Joos, F., Masson-Delmotte, V., Olago, D., Otto-Bliesner, B., Peltier, W., Rahmstorf, S., Ramesh, R., Raynaud, D., Rind, D., Solomina, O., Villalba, R., Zhang, D., 2007. Palaeo- climate. In: Solomon, S., Qin, D., Manning, M., Chen, Z., Marquis, M., Averyt, K. B., Tignor, M., Miller, H. L. (Eds.), Climate Change 2007: The Physical Science Basis. Contribution of Working Group I to the Fourth Assessment Report of the Intergovernmental Panel on Climate Change. Cambridge University Press, Cambridge, United Kingdom and New York, NY, USA, pp. 433-497.

Jones, P. D., New, M., Parker, D. E., Martin, S., Rigor, I. G., 1999. Surface air temperature and its changes over the past 150 years. Reviews of Geophysics $37,173-199$.

Joos, F., Gerber, S., Prentice, I. C., Otto-Bliesner, B. L., Valdes, P. J., 2004. Transient simulations of Holocenic atmospheric carbon dioxide and terrestrial carbon since the Last Glacial Maximum. Global Biogeochemical $\mathrm{Cy}-$ cles 18, GB2002, doi: 10.1029/2003GB002156.

Joos, F., Spahni, R., 2008. Rates of change in natural and anthropogenic radiative forcing over the past 20,000 years. Proceedings of the National Academy of Science 105, 1425-1430, doi: 10.1073/pnas.0707386105.

Jouzel, J., Masson-Delmotte, V., Cattani, O., Dreyfus, G., Falourd, S., Hoffmann, G., Minster, B., Nouet, J., Barnola, J. M., Chappellaz, J., Fischer, H., Gallet, J. C., Johnsen, S., Leuenberger, M., Loulergue, L., Luethi, D., Oerter, H., Parrenin, F., Raisbeck, G., Raynaud, D., Schilt, A., Schwander, J., Selmo, E., Souchez, R., Spahni, R., Stauffer, B., Steffensen, J. P., Stenni, B., Stocker, T. F., Tison, J. L., Werner, M., Wolff, E. W., 2007. Orbital and millennial Antarctic climate variability over the last 800000 years. Science 317, 793-796; doi: 10.1126/science.1141038.

Kiehl, J. T., 2007. Twentieth century climate model response and climate sensitivity. Geophysical Research Letters 34, L22710, doi: 10.1029/2007GL03183.

Kiehl, J. T., Trenberth, K. E., 1997. Earth's annual global mean energy budget. Bulletin of the American Meteorological Society 78, 197-208.

Knutti, R., Allen, M. R., Friedlingstein, P., Gregory, J. M., Hegerl, G. C., Meehl, G. A., Meinshausen, M., Murphy, J. M., Plattner, G.-K., Raper, S. C. B., Stocker, T. F., Stott, P. A., Teng, H., Wigley, T. M. L., 2008. A review of uncertainties in global temperature projections over the twenty-first century. Journal of Climate 21, 2651-2663, doi: 10.1175/2007JCLI2119.1.

Knutti, R., Hegerl, G. C., 2008. The equilibrium sensitivity of the Earth's temperature to radiation changes. Nature Geoscience 1, 735-743, doi: $10.1038 /$ ngeo337.

Knutti, R., Meehl, G. A., Allen, M. R., Stainforth, D. A., 2006. Constraining climate sensitivity from the seasonal cycle in surface temperature. Journal of Climate 19, 4224-4233.

Knutti, R., Stocker, T., Joos, F., Plattner, G.-K., 2002. Constraints on radiative forcing and future climate change from observations and climate model ensembles. Nature 416, 719-723.

Kohfeld, K. E., Harrison, S. P., 2001. DIRTMAP: the geological record of dust. Earth-Science Reviews 54 (1-3), 81 - 114, doi: 10.1016/S00128252(01)00042-3.

Köhler, P., Fischer, H., 2006. Simulating low frequency changes in atmospheric $\mathrm{CO}_{2}$ during the last 740000 years. Climate of the Past 2, 57-78.

Lambert, F., Delmonte, B., Petit, J. R., Bigler, M., Kaufmann, P. R., Hutterli, M. A., Stocker, T. F., Ruth, U., Steffensen, J. P., Maggi, V., 2008. Dustclimate couplings over the past 800,000 years from the EPICA Dome C ice core. Nature 452, 616-619, doi: 10.1038/nature06763.

Landais, A., Chappellaz, J., Delmotte, M., Jouzel, J., Blunier, T., Bourg, C., Caillon, N., Cherrier, S., Malaizé, B., Masson-Delmotte, V., Raynaud, D., Schwander, J., Steffensen, J. P., 2003. A tentative reconstruction of the last interglacial and glacial inception in Greenland based on new gas measurements in the Greenland Ice Core Project (GRIP) ice core. Journal of Geophysical Research 108(D18), 4563, doi: 10.1029/2002JD003147.

Legrand, M., 1987. Chemistry of Antarctic snow and ice. Journal of Physics 48/C1, 77-86.

Lisiecki, L. E., Raymo, M. E., 2005. A Pliocene-Pleistocene stack of 57 globally distributed benthic $\delta^{18} \mathrm{O}$ records. Paleoceanography 20, PA1003, doi: 10.1029/2004PA001071.

Lockwood, M., 2008. Recent oppositely directed trends in solar climate forcing and the global mean surface air temperature. III. Analysis of contributions to global mean air surface temperature rise. Proceedings of the Royal Society A 464, 1387-1404, doi: 10.1098/rspa.2007.0348.

Lockwood, M., Fröhlich, C., 2007. Recent oppositely directed trends in solar climate forcing and the global mean surface air temperature. Proceedings of the Royal Society A 463, 2447-2460, doi: 10.1098/rspa.2007.1880.

Lockwood, M., Fröhlich, C., 2008. Recent oppositely directed trends in solar climate forcing and the global mean surface air temperature. II. Different reconstructions of the total solar irradiance variation and dependence on response time scale. Proceedings of the Royal Society A 464, 1367-1385, doi: 
10.1098/rspa.2007.0347

Lohmann, U., Feichter, J., 2005. Global indirect aerosol effects: a review. Atmospheric Chemistry and Physics 5, 715-737.

Lohmann, U., Quaas, J., Kinne, S., j. Feichter, 2007. Different approaches for constraining global climate models of the anthropogenic indirect aerosol effect. Bulletin of the American Meteorological Society 88, 243-249, doi: 10.1175/BAMS-88-2-243.

Lorius, C., Jouzel, J., Raynaud, D., Hansen, J., Treut, H. L., 1990. The icecore record: climate sensitivity and future greenhouse warming. Nature 347 , 139-145.

Loulergue, L., Parrenin, F., Blunier, T., Barnola, J.-M., Spahni, R., Schilt, A., Raisbeck, G., Chappellaz, J., 2007. New constraints on the gas age-ice age difference along the EPICA ice cores, 0-50 kyr. Climate of the Past 3, 527540.

Loulergue, L., Schilt, A., Spahni, R., Masson-Delmotte, V., Blunier, T., Lemieux, B., Barnola, J.-M., Raynaud, D., Stocker, T. F., Chappellaz, J., 2008. Orbital and millennial-scale features of atmospheric $\mathrm{CH}_{4}$ over the past 800,000 years. Nature 453, 383-386, doi: 10.1038/nature06950.

Lüthi, D., Floch, M. L., Bereiter, B., Blunier, T., Barnola, J.-M., Siegenthaler, U., Raynaud, D., Jouzel, J., Fischer, H., Kawamura, K., Stocker, T. F., 2008. High-resolution $\mathrm{CO}_{2}$ concentration record 650,000-800,000 years before present. Nature 453, 379-382, doi: 10.1038/nature06949.

Mahowald, N. M., Muhs, D. R., Levis, S., Rasch, P. J., Yoshioka, M., Zender, C. S., Luo, C., 2006a. Changes in atmospheric mineral aerosols in response to climate: Last glacial period, preindustrial, modern, and doubled carbon dioxide climates. Journal of Geophysical Research 111, D10202, doi: 10.1029/2005JD006653.

Mahowald, N. M., Yoshioka, M., Collins, W. D., Conley, A. J., Fillmore, D. W., Coleman, D. B., 2006b. Climate response and ratiative forcing from mineral aerosols during the last glacial maximum, pre-industrial, current and doubled-carbon dioxide climates. Geophysical Research Letters 33, L20705, doi: 10.1029/2006GL026126.

Martínez-Garcia, A., Rosell-Mele, A., Geibert, W., Gersonde, R., Masqué, P., Gaspari, V., Barbante, C., 2009. Links between iron supply, marine productivity, sea surface temperature, and $\mathrm{CO}_{2}$ over the last 1.1 Ma. Paleoceanography 24, PA1207, doi: 10.1029/2008PA001657.

Masson-Delmotte, V., Kageyama, M., Braconnot, P., Charbit, S., Krinner, G., Ritz, C., Guilyardi, E., Jouzel, J., Abe-Ouchi, A., Cruci, M., Gladstone, R. M., Hewitt, C. D., Kitoh, A., LeGrande, A. N., Marti, O., Merkel, U., Ohgaito, T. M. R., Otto-Bliesner, B., Peltier, W. R., Ross, I., Valdes, P. J., Vettoretti, G., Weber, S. L., Wolk, F., YU, Y., 2006. Past and future polar amplification of climate change: climate model intercomparisons and icecore constraints. Climate Dynamics 26, 513-529.

Masson-Delmotte, V., Stenni, B., Pol, K., Braconnot, P., Cattani, O., Falourd, S., Jouzel, J., Landais, A., Minster, B., Petit, J. R., Johnsen, S., Röthlisberger, R., Chappellaz, J., Hansen, J., 2009. EPICA Dome C record of glacial and interglacial intensities. Quaternary Science Reviews, submitted to this issue.

Menon, S., Hansen, J., Nazarenko, L., Luo, Y., 2002. Climate effects of black carbon aerosols in China and India. Science 297, 2250-2253.

Milankovitch, M., 1941. Kanon der Erdbestrahlung und seine Anwendung auf das Eiszeitenproblem, Special Publications Vol. 132. Vol. 33 of Section Mathematics and Natural Sciences. Royal Serbian Acadademy, Belgrad.

Mix, A. C., Bard, E., Schneider, R., 2001. Environmental processes of the ice age: land, oceans, glaciers (EPILOG). Quaternary Science Reviews 20, $627-657$.

Monnin, E., Indermühle, A., Dällenbach, A., Flückiger, J., Stauffer, B., Stocker, T. F., Raynaud, D., Barnola, J.-M., 2001. Atmospheric $\mathrm{CO}_{2}$ concentrations over the last glacial termination. Science 291, 112-114.

Muscheler, R., Joos, F., Beer, J., Müller, S. A., Vonmoos, M., Snowball, I., 2007. Solar activity during the last $1000 \mathrm{yr}$ inferred from radionucilde records. Quaternary Science Reviews 26, 82-97, doi: 10.1016/j.quascirev.2006.07.012

Myhre, G., Highwood, E. J., Shine, K. P., Stordal, F., 1998. New estimates of radiative forcing due to well mixed greenhouse gases. Geophysical Research Letters 25, 2715-2718.

NorthGRIP-members, 2004. High-resolution record of Northern Hemisphere climate extending into the last interglacial period. Nature 431, 147-151.

Oerlemans, J., Dahl-Jensen, D., Masson-Delmotte, V., 2006. Ice sheets and sea level. Science 313, 1043-1044.

Otto-Bliesner, B. L., Marshall, S. J., Overpeck, J. T., Miller, G. H., Hu A., CAPE-Interglacial-Project-members, 2006. Simulating Arctic climate warmth and icefield retreat in the Last Interglacial. Science 311, 1751-1753, doi: $10.1126 /$ science. 1120808 .
Otto-Bliesner, B. L., Schneider, R., Brady, E. C., Kucera, M., Abe-Ouchi, A., Bard, E., Braconnot, P., Crucifix, M., Hewitt, C., Kageyama, M., Marti, O. Paul, A., Rosell-Melé, A., Waelbroeck, C., Weber, S. L., Weinelt, M., Yu, Y., 2009. A comparison of PMIP2 model simulations and the MARGO proxy reconstruction for tropical sea surface temperatures at last glacial maximum. Climate Dynamics 32, 799-815, doi: 10.1007/s00382-008-0509-0.

Pallé, E., Montañés-Rodriguez, P., Goode, P. R., Koonin, S. E., Wild, M., Casadio, S., 2005. A multi-data comparison of shortwave climate forcing changes. Geophysical Research Letters 32, L21702, doi: 10.1029/2005GL023847.

Parkinson, C. L., Cavalieri, D. J., 2008. Arctic sea ice variability and trends, 1979-2006. Journal of Geophysical Research 113, C07003, doi: 10.1029/2007JC004558.

Parrenin, F., Barnola, J.-M., Beer, J., Blunier, T., Castellano, E., Chappellaz, J., Dreyfus, G., Fischer, H., Fujita, S., Jouzel, J., Kawamura, K., LemieuxDudon, B., Loulergue, L., Masson-Delmotte, V., Narcisi, B., Petit, J.-R., Raisbeck, G., Raynaud, D., Ruth, U., Schwander, J., Severi, M., Spahni, R., Steffensen, J. P., Svensson, A., Udisti, R., Waelbroeck, C., Wolff, E., 2007. The EDC3 chronology for the EPICA Dome C ice core. Climate of the Past 3, 485-497.

Payne, R. E., 1972. Albedo of the Sea Surface. Journal of the Atmospheric Sciences 29, 959-970.

Peixoto, J. P., Oort, A. H., 1992. Physics of Climate. American Institute of Physics, New York.

Peltier, W. R., 2004. Global glacial isostasy and the surface of the ice-age Earth: the ICE-5G (VM2) model and GRACE. Annual Review in Earth and Planetary Sciences 32, 111-149, doi: 10.1146/annurev.earth.32.082503.144359.

Petit, J. R., Jouzel, J., Raynaud, D., Barkov, N. I., Barnola, J.-M., Basile, I., Bender, M., Chappellaz, J., Davis, M., Delaygue, G., Delmotte, M., Kotlyakov, V. M., Legrand, M., Lipenkov, V. Y., Lorius, C., Pépin, L., Ritz, C., Saltzman, E., Stievenard, M., 1999. Climate and atmospheric history of the past 420,000 years from the Vostok ice core, Antarctica. Nature 399, 429-436.

Piani, C., Frame, D. J., Stainforth, D. A., Allen, M. R., 2005. Constraints on climate change from a multi-thousand member ensemble of simulations. Geophysical Research Letters 32, L23825, doi: 10.1029/2005GL024452.

Plattner, G.-K., Knutti, R., Joos, F., Stocker, T. F., von Bloh, W., Brovkin, V., Cameron, D., Driesschaert, E., Dutkiewicz, S., Eby, M., Edwards, N. R., Fichefet, T., Hargreaves, J. C., Jones, C. D., Loutre, M. F., Matthews, H. D., Mouchet, A., Müller, S. A., Nawrath, S., Price, A., Sokolov, A., Strassmann, K. M., Weaver, A. J., 2008. Long-term climate commitments projected with climate-carbon cycle models. Journal of Climate 21, 2721-2751, doi: 10.1175/2007JCLI1905.1.

Prentice, I. C., Jolly, D., BIOME 6000 participants, 2000. Mid-Holocene and glacial-maximum vegetation geography of northern continents and Africa. Journal of Biogeography 27, 507-519.

Qu, X., Hall, A., 2005. Surface contribution to planetary albedo variability in cryosphere regions. Journal of Climate 18, 5239-5252.

Ramanathan, V., Crutzen, P. J., Kiehl, J. T., Rosenfeld, D., 2001. Aerosols, climate, and the hydrological cycle. Science 294, 2119-2124.

Ramanathan, V., Inamdar, A., 2006. The radiative forcing due to clouds and water vapor. In: Kiehl, J. T., Ramanathan, V. (Eds.), Frontiers of Climate Modeling. Cambridge University Press, Cambridge, pp. 119-151.

Randall, D. A., Wood, R., Bony, S., Colman, R., Fichefet, T., Fyfe, J., Kattsov, V., Pitman, A., Shukla, J., Srinivasan, J., Stouffer, R., Sumi, A., Taylor, K., 2007. Climate Models and Their Evaluation. In: Solomon, S., Qin, D., Manning, M., Chen, Z., Marquis, M., Averyt, K. B., Tignor, M., Miller, H. L. (Eds.), Climate Change 2007: The Physical Science Basis. Contribution of Working Group I to the Fourth Assessment Report of the Intergovernmental Panel on Climate Change. Cambridge University Press, Cambridge, United Kingdom and New York, NY, USA, pp. 589-662.

Revel-Rolland, M., Deckker, P. D., Delmonte, B., Hesse, P., Magee, J., BasileDoelsch, I., Grousset, F., Bosch, D., 2006. Eastern Australia: A possible source of dust in East Antarctica interglacial ice. Earth and Planetary Science Letters 249, 1-13, doi:10.1016/j.eps1.2006.06.028

Rind, D., 2002. The sun's role in climate variations. Science 296, 673-677.

Roe, G. H., Baker, M. B., 2007. Why Is climate sensitivity so unpredictable? Science 318 (5850), 629-632, doi: 10.1126/science.1144735.

Romanova, V., Lohmann, G., Grosfeld, K., Butzin, M., 2006. The relative role of oceanic heat transport and orography on glacial climate. Quaternary Science Reviews 25, 832-845, doi: 10.1016/j.quascirev.2005.07.007.

Röthlisberger, R., Mudelsee, M., Bigler, M., de Angelis, M., Fischer, H., Hansson, M., Lambert, F., Masson-Delmotte, V., Sime, L., Udisti, R., Wolff, E. W., 2008. The Southern Hemisphere at glacial terminations: insights from 
the Dome C ice core. Climate of the Past 4, 345-356.

Sagan, C., Mullen, G., 1972. Earth and Mars: evoluation of atmospheres and surface temperatures. Science 177, 52-56.

Saltzman, B., Hansen, A. R., Maasch, K. A., 1984. The late Quaternary glaciations as the response of a three-component feedback system to Earth-orbital forcing. Journal of the Atmospheric Sciences 41, 3380-3389.

Sarnthein, M., Pflaumann, U., Weinelt, M., 2003. Past extent of sea ice in the northern North Atlantic inferred from foraminiferal paleotemperature estimates. Paleoceanography 18, 1047, doi: 10.1029/2002PA000771.

Schilt, A., Baumgartner, M., Blunier, T., Schwander, J., Spahni, R., Fischer, H., Stocker, T. F., 2009. Glacial-interglacial and millennial-scale variations in the atmospheric nitrous oxide concentration during the last 800000 years. Quaternary Science Reviews, in press, this issue, doi: 10.1016/j.quascirev.2009.03.011.

Schneider, D. P., Ammann, C. M., Otto-Bliesner, B. L., Kaufman, D. S., Aug. 2009. Climate response to large, high-latitude and low-latitude volcanic eruptions in the Community Climate System Model. Journal of Geophysical Research 114, D15101, doi: 10.1029/2008JD011222.

Schneider von Deimling, T., Ganopolski, A., Held, H., Rahmstorf, S., 2006 a. Climate sensitivity estimated from ensemble simulations of glacial climate. Climate Dynamics 27, 149-163, doi: 10.1007/s00382-006-0126-8.

Schneider von Deimling, T., Ganopolski, A., Held, H., Rahmstorf, S., 2006b. How cold was the Last Glacial Maximum? Geophysical Research Letters 33, L14709, doi: 10.1029/2006GL026484.

Siegenthaler, U., Stocker, T. F., Monnin, E., Lüthi, D., Schwander, J., Stauffer, B., Raynaud, D., Barnola, J.-M., Fischer, H., Masson-Delmotte, V., Jouzel, J., 2005. Stable carbon cycle-climate relationship during the late Pleistocene. Science 310, 1313-1317, doi: 10.1126/science.1120130.

Soden, B. J., Broccoli, A. J., Hemler, R. S., Oct. 2004. On the Use of Cloud Forcing to Estimate Cloud Feedback. Journal of Climate 17 (19), 3661$3665,10.1175 / 1520-0442(2004) 017<3661$ :OTUOCF $>2.0 . C O ; 2$.

Soden, B. J., Held, I. M., 2006. An assessment of climate feedbacks in coupled ocean-atmosphere models. Journal of Climate 19, 3354-33360.

Soden, B. J., Held, I. M., Colman, R., Shell, K. M., Kiehl, J. T., Shields, C. A., 2008. Quantifying climate feedbacks using radiative kernels. Journal of Climate 21, 3504-3520, doi: 10.1175/2007JCLI2110.1.

Soden, B. J., Wetherald, R. T., Stenchikov, G. L., Robock, A., 2002. Global cooling after the eruption of Mount Pinatubo: a test of climate feedback by water vapor. Science 296, 727-730.

Solomon, S., Qin, D., Manning, M., Chen, Z., Marquis, M., Averyt, K. B., Tignor, M., Miller, H. L. (Eds.), 2007. Climate Change 2007: The Physical Science. Contribution of Working Group I to the Fourth Assessment Report of the Intergovernmental Panel on Climate Change. Cambridge University Press, Cambridge, U.K. and New York, NY, USA.

Spahni, R., Chappellaz, J., Stocker, T. F., Loulergue, L., Hausammann, G., Kawamura, K., Flückiger, J., Schwander, J., Raynaud, D., MassonDelmotte, V., Jouzel, J., 2005. Atmospheric methane and nitrous oxide of the late Pleistocene from Antarctic ice cores. Science 310, 1317-1321, doi: 10.1126/science. 1120132 .

Stainforth, D. A., Aina, T., Christensen, C., Collins, M., Faull, N., Frame, D. J. Kettleborough, J. A., Knight, S., Martin, A., Murphy, J. M., Piani, C., Sexton, D., Smith, L. A., Spicer, R. A., Thorpe, A. J., Allen, M. R., 2005. Uncertainty in predictions of the climate response to rising levels of greenhouse gases. Nature 433, 403-406, doi:10.1038/nature03301.

Stirling, C. H., Esat, T. M., Lambeck, K., McCulloch, M. T., 1998. Timing and duration of the Last Interglacial: evidence for a restricted interval of widespread coral reef growth. Earth and Planetary Science Letters 160, 745762 .

Stroeve, J. C., Box, J. E., Fowler, C., Haran, T., Key, J., 2001. Intercomparison between in situ and AVHRR Polar Pathfinder-Derived Surface albedo over Greenland. Remote Sensing of Environment 75, 360-374, doi:10.1016/S0034-4257(00)00179-6.

Tanaka, K., Raddatz, T., O’Neill, B. C., Reick, C. H., Aug. 2009. Insufficient forcing uncertainty underestimates the risk of high climate sensitivity. Geophysical Research Letters 36, L16709, doi: 10.1029/2009GL039642.

Tarasov, P., Williams, J. W., Andreev, A., Nakagawa, T., Bezrukova, E., Herzschuh, U., Igarashi, Y., Müller, S., Werner, K., Zheng, Z., 2007. Satellite- and pollen-based quantitative woody cover reconstructions for northern Asia: Verification and application to late-Quaternary pollen data. Earth and Planetary Science Letters 264, 284-298, doi: 10.1016/j.eps1.2007.10.007.

Taylor, K. E., Crucifix, M., Braconnot, P., Hewitt, C. D., Doutriaux, C., broccoli, A. J., Mitchell, J. F. B., Webb, M. J., 2007. Estimating shortwave radiative forcing and response in climate models. Journal of Climate 20, 2530-
2543, doi: $10.1175 /$ jcli4143.1.

Tegen, I., 2003. Modeling the mineral dust aerosol cycle in the climate system. Quaternary Science Reviews 22, 1821-1834.

Vavrus, S., 2007. The role of terrestrial snow cover in the climate system. Climate Dynamics 29, 73-88, doi: 10.1007/s00382-007-0226-0.

Vuuren, D. P. V., Meinshausen, M., Plattner, G.-K., Joos, F., Strassmann, K. M., Smith, S. J., Wigley, T. M. L., Raper, S. C. B., Riahi, K., de la Chesnaye, D., den Elzen, M. G. J., Fujino, J., Jiang, K., Nakivenovic, N., Paltsev, S., Reilly, J. M., 2008. Temperature increase of 21 st century mitigation scenarios. Proceedings of the National Academy of Science 105, 15258-15262, doi: 10.1073/pnas.0711129105.

Waelbroeck, C., Labeyrie, L., Michel, E., Duplessy, J. C., McManus, J. F., Lambeck, K., Balbon, E., Labracherie, M., 2002. Sea-level and deep water temperature changes derived from benthic foraminifera isotopic records. Quaternary Science Reviews 21, 295-305.

Wang, Y. M., Lean, J. L., Sheeley, N. R., 2005. Modeling the sun's magnetic field and irradiance since 1713. The Astrophysical Journal 625, 522-538.

Wanner, H., Beer, J., Bütikofer, J., Crowley, T. J., Cubasch, U., Flückiger, J., Goosse, H., Grosjean, M., Joos, F., Kaplan, J. O., Küttel, M., Müller, S. A., Prentice, I. C., Solomina, O., Stocker, T. F., Tarasov, P., Wagner, M., Widmann, M., 2008. Mid- to Late Holocene climate change: an overview. Quaternary Science Reviews 27, 1791-1828, doi: 10.1016/j.quascirev.2008.06.013

Wanner, W., Strahler, A. H., Hu, B., Lewis, P., Muller, J.-P., Li, X., Schaaf, C. L. B., Barnsley, M. J., 1997. Global retrieval of bidirectional reflectance and albedo over land from EOS MODIS and MISR data: Theory and algorithm. Journal of Geophysical Research 102(D14), 17143-17161.

Wielicki, B. A., Wong, T., Loeb, N., Minnis, P., Priestley, K., Kandel, R., 2005. Changes in Earth's albedo measured by satellite. Science 308, 825, doi: $10.1126 /$ science. 1106484 .

Winckler, G., Anderson, R. F., Fleisher, M. Q., McGee, D., Mahowald, N., 2008. Covariant glacial-interglacial dust fluxes in the equatorial Pacific and Antarctica. Science 320, 93-96, doi: 10.1126/science.1150595.

Wolff, E. W., Fischer, H., Fundel, F., Ruth, U., Twarloh, B., Littot, G. C., Mulvaney, R., Röthlisberger, R., de Angelis, M., Boutron, C. F., Hansson, M., Jonsell, U., Hutterli, M., Lambert, F., Kaufmann, P., Stauffer, B., Stocker, T. F., Steffensen, J. P., Bigler, M., Siggaard-Andersen, M. L., Udisti, R., Becagli, S., Castellano, E., Severi, M., Wagenbach, D., Barbante, C., Gabrielli, P., Gaspari, V., 2006. Southern Ocean sea-ice extent, productivity and iron fluxes over the past eight glacial cycles. Nature 440, 491-496, doi: 10.1038/nature04614.

Wolff, E. W., Rankin, A. M., Röthlisberger, R., 2003. An ice core indicator of Antarctic sea ice production? Geophysical Research Letters 30, 2158, doi: 10.1029/2003GL018454

Yokohata, T., Emori, S., Nozawa, T., Tsushima, Y., Ogura, T., Kimoto, M., Oct. 2005. A simple scheme for climate feedback analysis. Geophysical Research Letters 32, L19703, 10.1029/2005GL023673.

Yokoyama, Y., Lambeck, K., Dekker, P. D., Johnston, P., Fifield, L. K., 2000. Timing of the Last Glacial Maximum from observed sea-level minima. Nature 406, 713-716.

Zweck, C., Huybrechts, P., 2005. Modelling of the northern hemisphere ice sheets during the last glacial cycle and glaciological sensitivity. Journal of Geophysical Research 110, D07103, doi: 10.1029/2004JD005489. 
Table 1: Summary for different processes including the uncertainty estimates and results averaged over the EPILOG LGM definition (Mix et al., 2001) of 23-19 kyr BP. Processes which are not considered in the final compilation are in italics and indented. We calculate the error propagation of the uncertainties (column 2) to the overall uncertainty of each individual processes by the square root of the sum of the squares (one standard deviation) assuming independence of the different contributors. The uncertainty of a combination of processes (e.g. all GHG) is also calculated as the square root of the sum of the squares (lower estimate). However, as this also requires independency of the different processes (which is not always the case) we additionally calculate an upper estimated uncertainty by the sum of the individual standard deviations. This compilation here neglects feedbacks from water vapour, lapse rate and clouds.

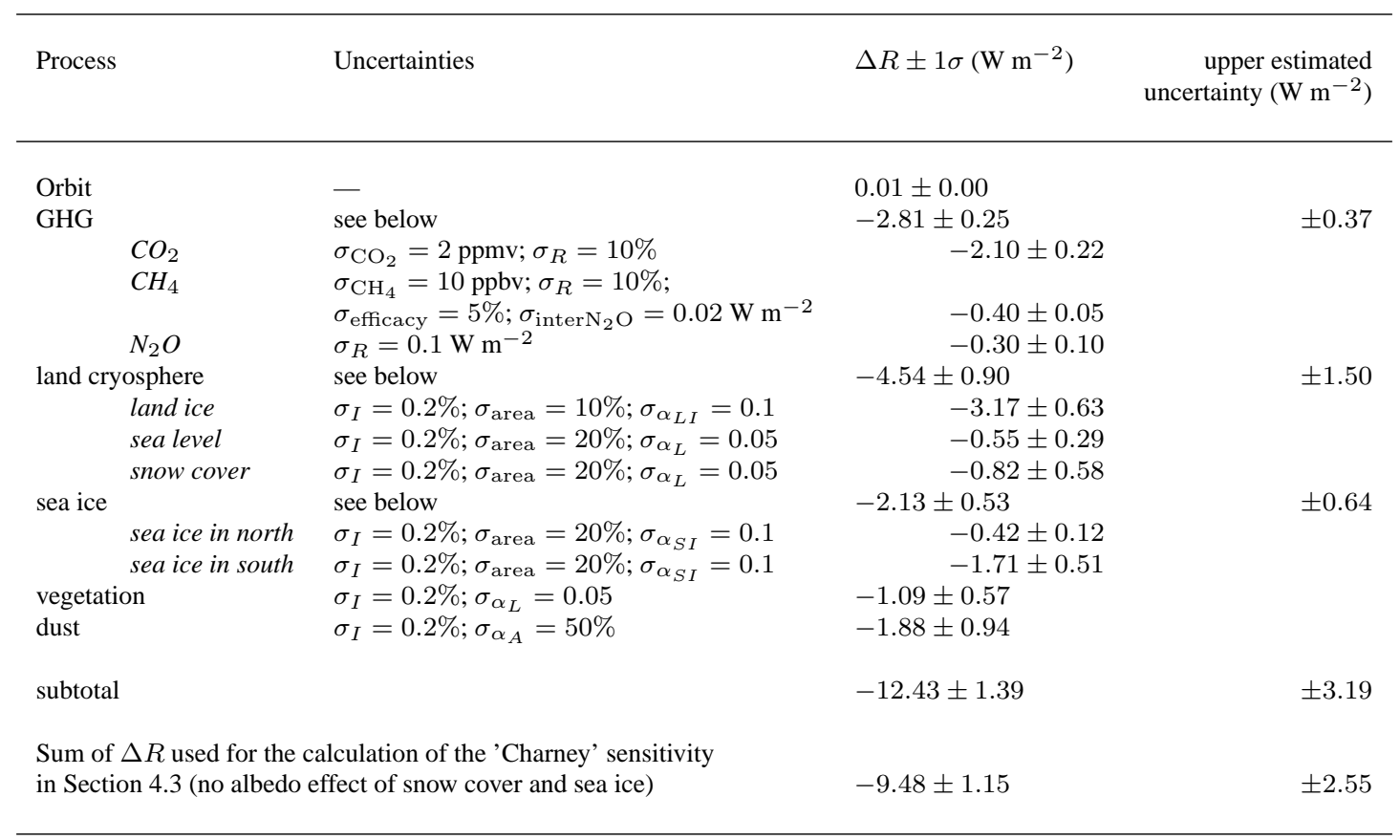




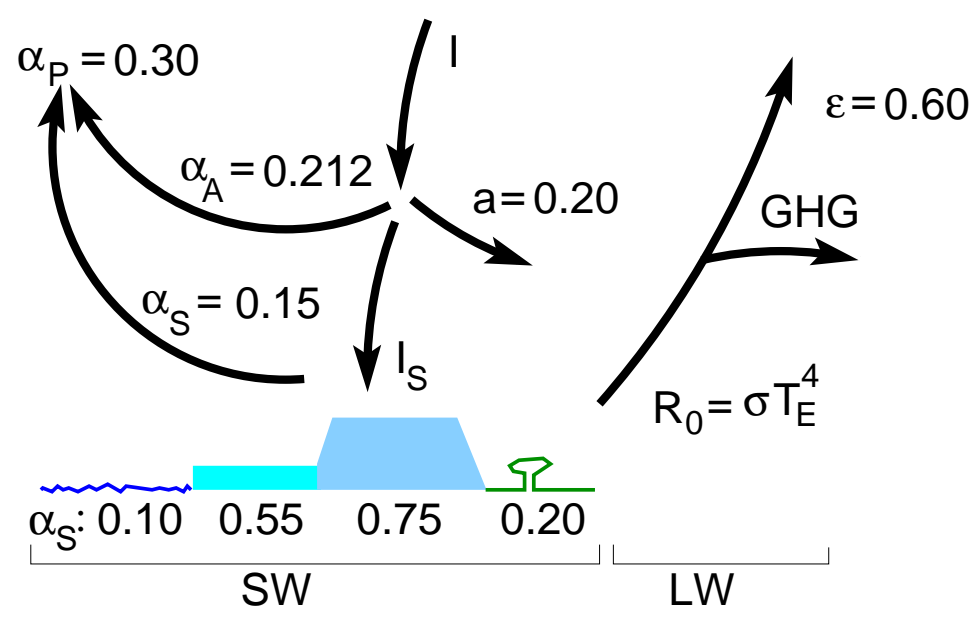

Figure 1: Global annual mean radiative budget of Earth's atmosphere including present days numbers with the amount of details used in our approach (modified after Kiehl and Trenberth, 1997). Short-wave (SW) incoming radiation $I$ is balanced by long-wave (LW) outgoing radiation, which is a function of Earth's temperature $T_{E}$. SW radiation reaching Earth's surface $I_{S}$ is influenced by atmospheric reflection $\alpha_{A}$ and absorption $a$. Greenhouse gases (GHG) reduce the amount of LW radiation $R$ leaving the atmosphere. This is also reflected in the effective emissivity $\varepsilon$ of the Earth. The mean surface albedo $\alpha_{S}$ is distinguished for different surfaces (from left to right: ocean, sea ice, land ice and ice-free land). The planetary albedo $\alpha_{P}$ combines both $\alpha_{S}$ and $\alpha_{A}$. The atmospheric albedo $\alpha_{A}$ is in our approach only varied due to atmospheric dust loading.

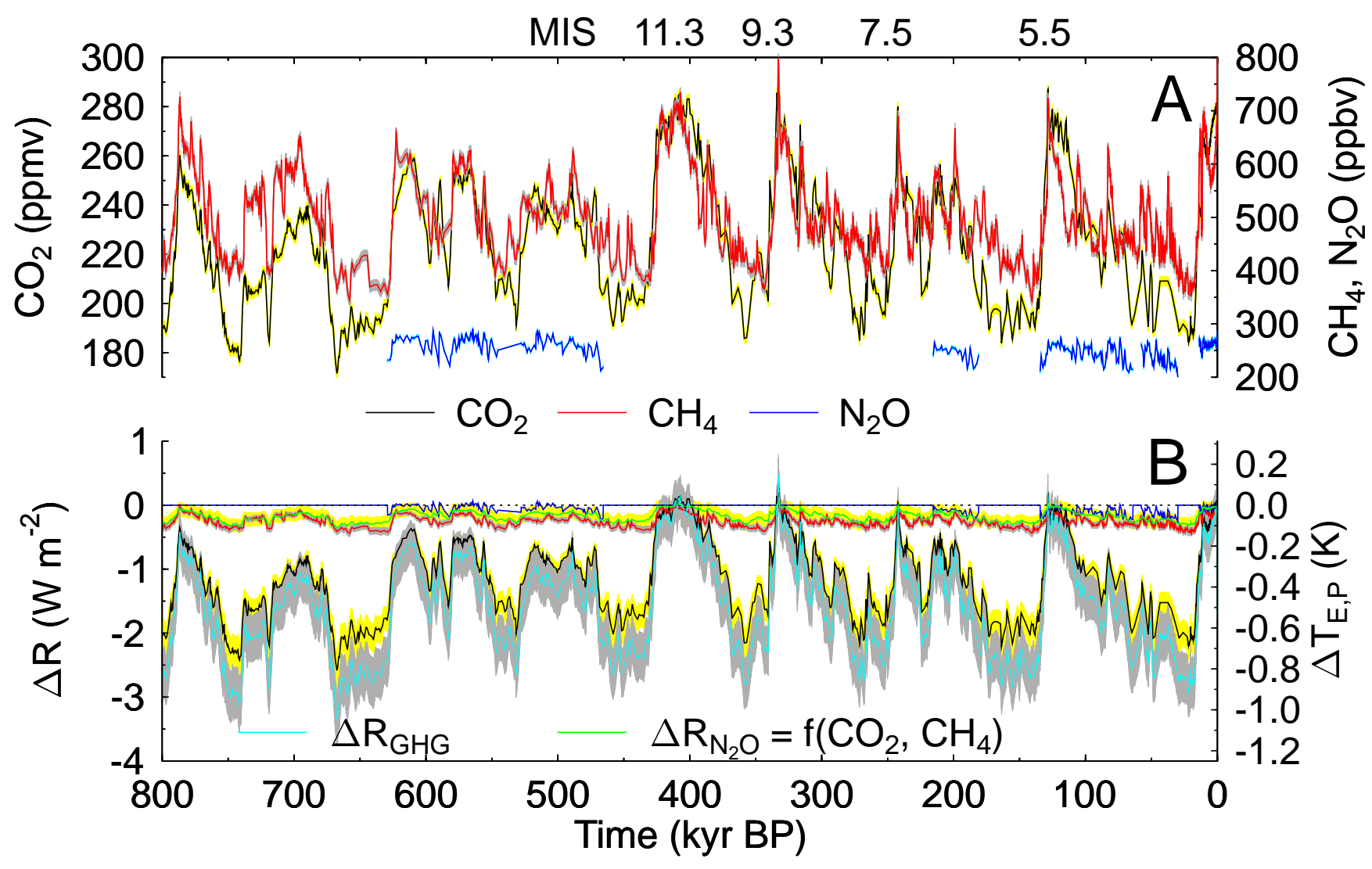

Figure 2: Variations in the GHG records. (A) Variations of atmospheric $\mathrm{CO}_{2}, \mathrm{CH}_{4}$ and $\mathrm{N}_{2} \mathrm{O}$. $\mathrm{CH}_{4}$ and $\mathrm{N}_{2} \mathrm{O}$ are solely measured on EPICA Dome C (Spahni et al., 2005; Loulergue et al., 2008), while $\mathrm{CO}_{2}$ is a composite from Vostok (Petit et al., 1999) and EPICA Dome C data (Monnin et al., 2001; Siegenthaler et al., 2005; Lüthi et al., 2008). All gas records are on the EDC3_gas_a age scale (Loulergue et al., 2007). (B) Perturbation in the radiative budget due to the three gases and the total GHG forcing including the lower uncertainty ranges $\left(\Delta R_{\mathrm{GHG}}=\Delta R_{\mathrm{CO}_{2}}+\Delta R_{\mathrm{CH}_{4}}+\Delta R_{\mathrm{N}_{2} \mathrm{O}}\right)$. The effect of methane $\left(\Delta R_{\mathrm{CH}}\right)$ contains also the indirect effect via stratospheric $\mathrm{H}_{2} \mathrm{O}$ and tropospheric $\mathrm{O}_{3}, \Delta R_{\mathrm{N}_{2}} \mathrm{O}$ is calculated either directly out of $\mathrm{N}_{2} \mathrm{O}$ or is due the large data gaps based on changes in $\mathrm{CO}_{2}$ and $\mathrm{CH}_{4}$, the latter is used to calculate $\Delta R_{\mathrm{GHG}}$. The right y-axis shows the temperature anomalies $\Delta T_{E, P}$ of the Planck feedback. 

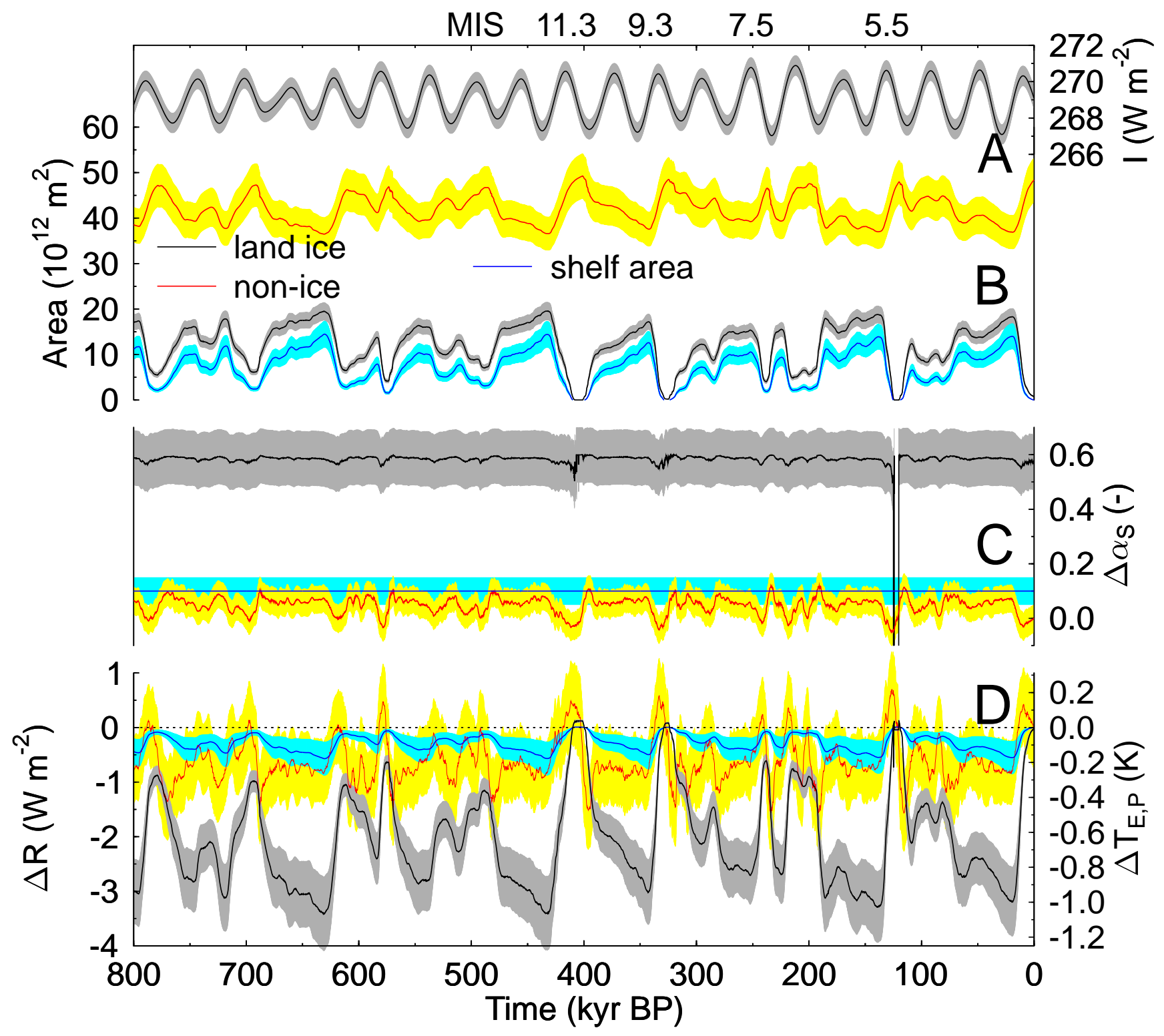

Figure 3: Albedo feedback from the land cryosphere. (A) Annual mean local insolation at the top of the atmosphere $I$ at $40-80^{\circ} \mathrm{N}$ (Berger, 1978). (B) Area changes of (i) land ice sheets (North America and Eurasia only) and (ii) land without ice (both in $40-80^{\circ} \mathrm{N}$ deconvoluted from the benthic $\delta^{18} \mathrm{O}$ stack LR04 (Bintanja et al., 2005; Lisiecki and Raymo, 2005)), and (iii) global shelf area effected by sea level change based on own assumptions. (C) Changes in surface albedo $\alpha_{S}$ on areas plotted in (B), those over land ice and ice-free land are again simulation results from (Bintanja et al., 2005), while albedo change on exposed shelves are our own assumption. (D) Perturbation in the radiative budget caused by the albedo feedback from land ice sheets, snow cover on non-glaciated land $\left(40-80^{\circ} \mathrm{N}\right)$ and sea level change. The right $\mathrm{y}$-axis shows the temperature anomalies $\Delta T_{E, P}$ of the Planck feedback. The legend is valid for sub-figures $\mathrm{B}, \mathrm{C}$, and $\mathrm{D}$. The albedo over northern hemispheric land ice sheets is undefined around $130 \mathrm{kyr}$, because these ice sheets disappeared completely. Ice sheets did not vanish completely in the other interglacials, thus albedo over land ice was defined during all other times. 


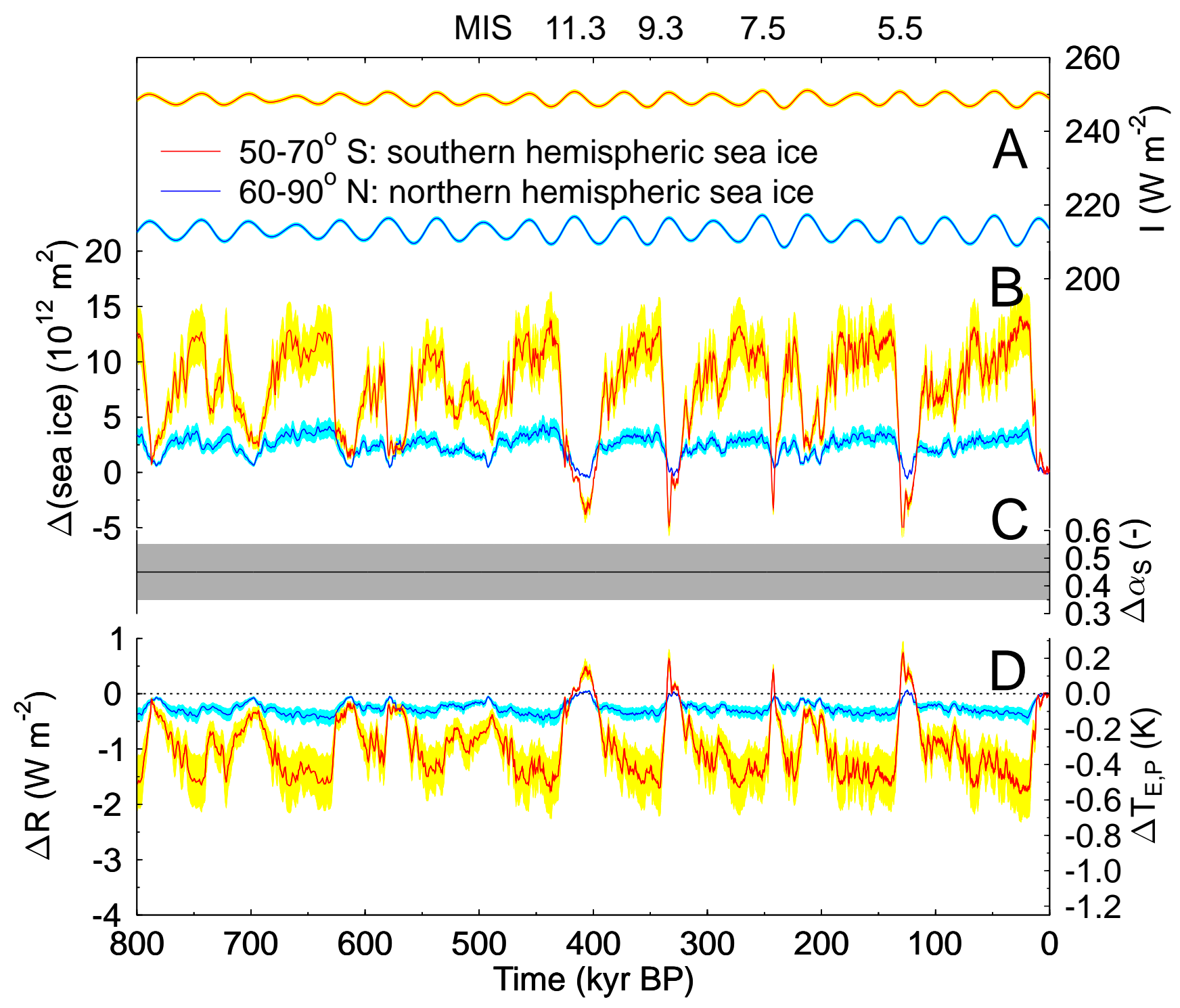

Figure 4: Sea ice-albedo feedback. (A) Annual mean local insolation at the top of the atmosphere $I$ at $50-70^{\circ} \mathrm{S}$ and $60-90^{\circ} \mathrm{N}$, the regions of SH and NH sea ice, respectively (Berger, 1978). (B) Area changes of sea ice. Estimates are based on (i) Antarctic temperature changes for the SH (Jouzel et al., 2007) and (ii) northern hemispheric temperature changes for the NH (Bintanja et al., 2005; Lisiecki and Raymo, 2005), linearly related to LGM to present sea ice area reconstructions. (C) Assumed changes in surface albedo $\alpha_{S}$ from open ocean to sea ice. (D) Perturbation in the radiative budget caused by the sea ice-albedo feedback. The right y-axis shows the temperature anomalies $\Delta T_{E, P}$ of the Planck feedback. The legend is valid for sub-figures A, B, and D. 

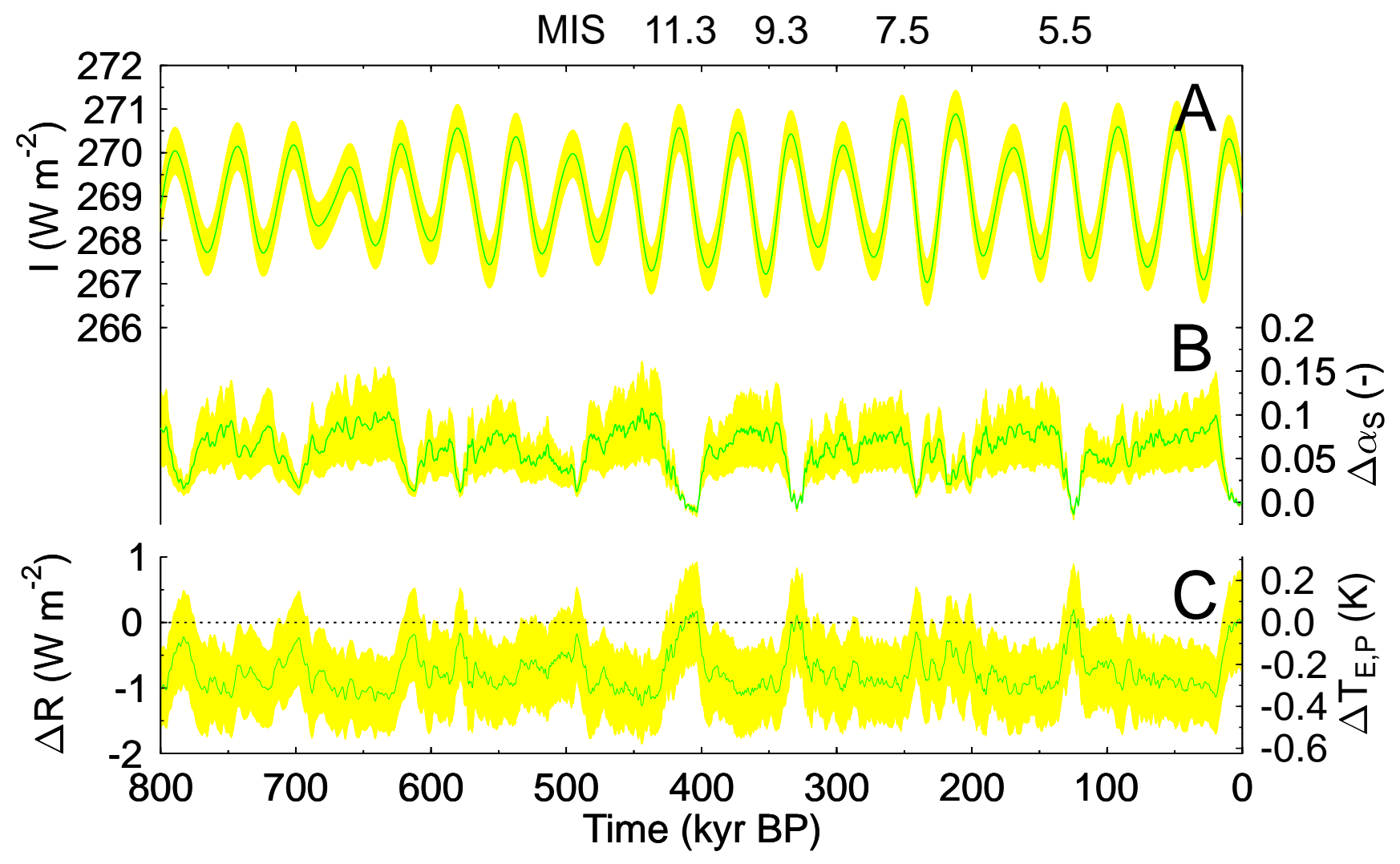

Figure 5: Vegetation-albedo feedback. (A) Annual mean local insolation at the top of the atmosphere $I$ at $40-80^{\circ} \mathrm{N}$ (Berger, 1978). (B) Changes in surface albedo $\alpha_{S}$ over vegetation in $40-80^{\circ} \mathrm{N}$ calculated out of continental surface air temperature changes (Bintanja et al., 2005). (C) Perturbation in the radiative budget caused by the vegetation-albedo feedback. Changes are focused on $40-80^{\circ} \mathrm{N}$. The right y-axis shows the temperature anomalies $\Delta T_{E, P}$ of the Planck feedback. 


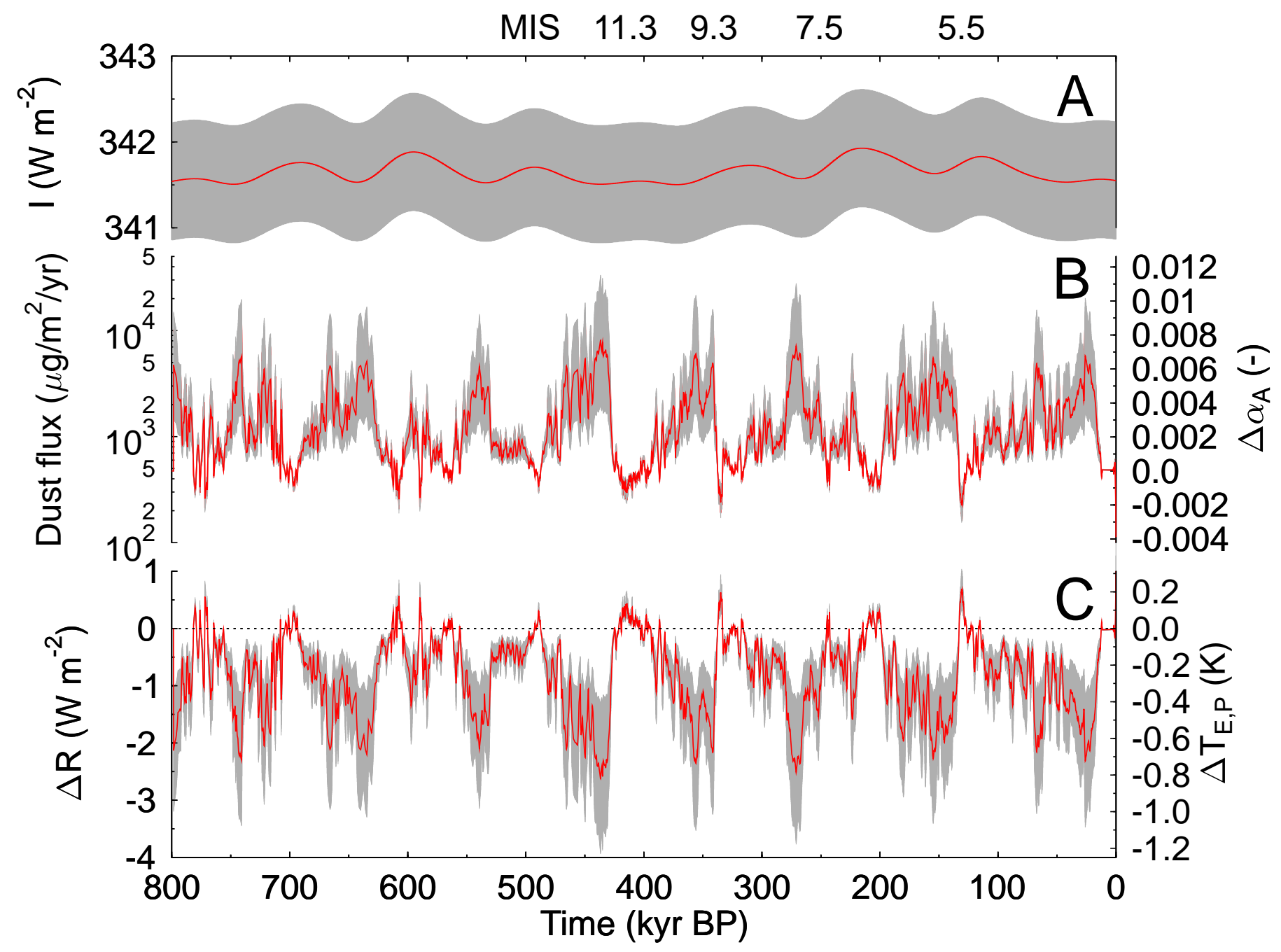

Figure 6: Dust-albedo feedback. (A) Annual and global mean local insolation I (Berger, 1978). (B) Variation in dust flux measured in EPICA Dome C (Lambert et al., 2008) on the EDC3 age scale (Parrenin et al., 2007) (left y-axis) and calculated changes in atmospheric albedo $\alpha_{A}$ (right y-axis). Original data are averaged with a 1000 year running mean. (C) Perturbation in the radiative budget caused by the dust-albedo feedback. The right y-axis shows the temperature anomalies $\Delta T_{E, P}$ of the Planck feedback. 


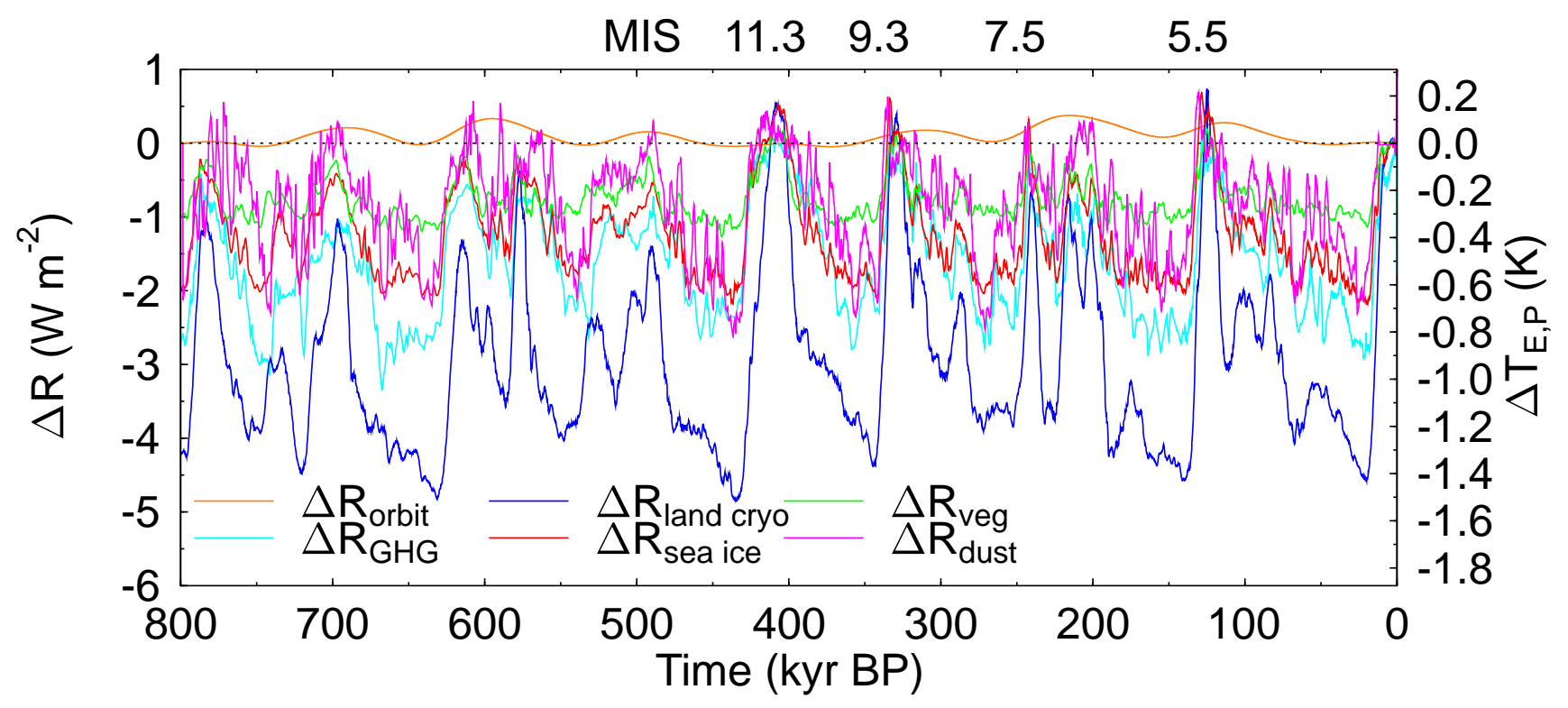

Figure 7: A compilation of individual radiative forcings due to orbital variation $\left(\Delta R_{\text {orbit }}\right)$, the $\mathrm{GHG} \mathrm{CO}_{2}, \mathrm{CH}_{4}$ and $\mathrm{N}_{2} \mathrm{O}\left(\Delta R_{\mathrm{GHG}}\right)$, land cryosphere including ice sheets and associated sea level change and snow cover $\left(\Delta R_{\text {land cryo }}\right)$, sea ice $\left(\Delta R_{\text {sea ice }}\right)$, atmospheric dust loadings $\left(\Delta R_{\text {dust }}\right)$, and vegetation $\left(\Delta R_{\mathrm{veg}}\right)$. Feedbacks from water vapour, lapse rate, and clouds are omitted here.

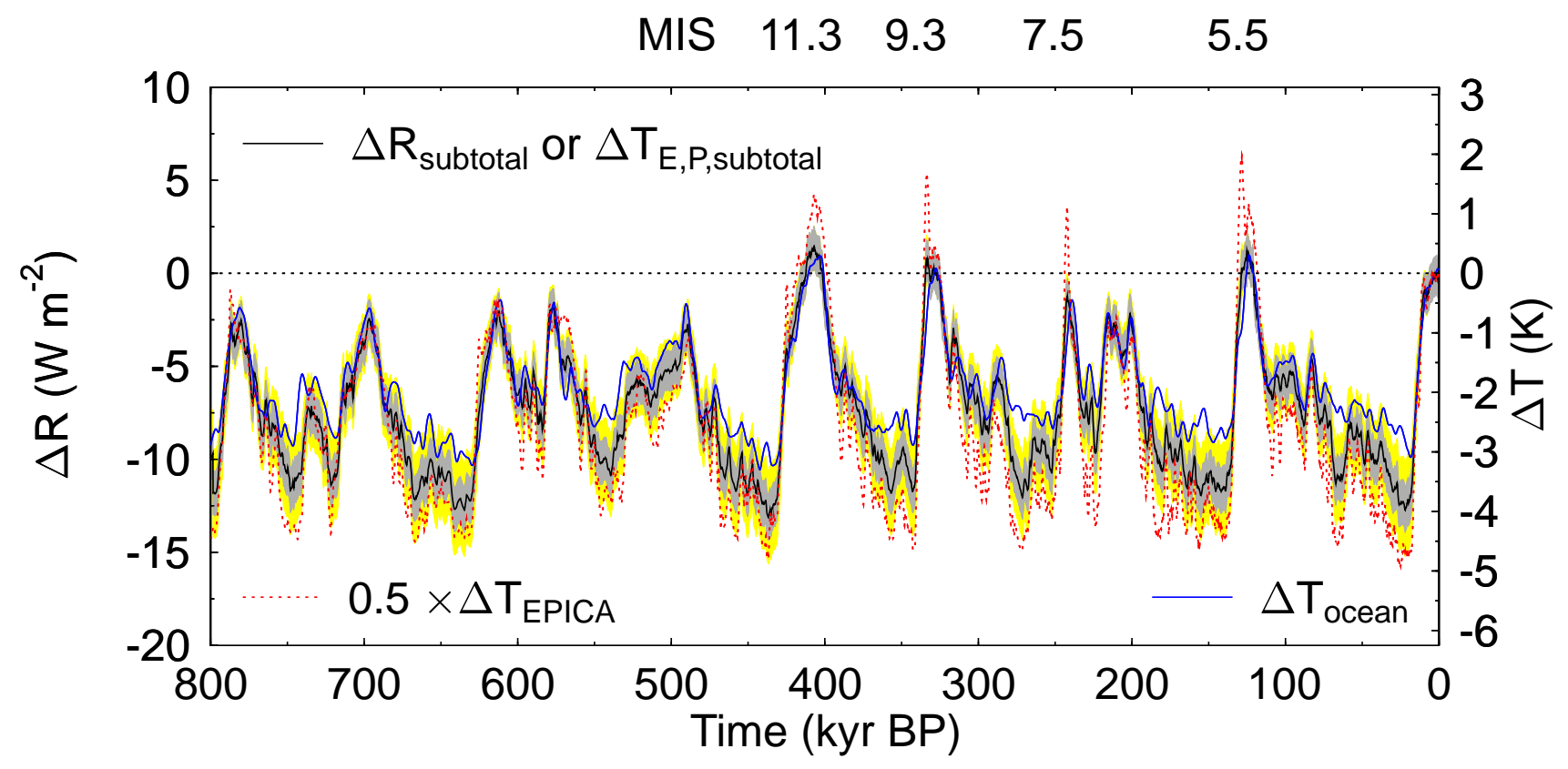

Figure 8: Sum of radiative forcing $\Delta R_{\text {subtotal }}$ (left y-axis) of individual processes and its respective temperature anomaly $\Delta T_{E, P \text {,subtotal }}$ (right y-axis) considering only the Planck feedback but without those of water vapour, lapse rate and clouds $\left(\Delta R_{\text {subtotal }}=\Delta R_{\text {orbit }}+\Delta R_{\mathrm{GHG}}+\Delta R_{\text {land cryo }}+\Delta R_{\text {sea ice }}+\right.$ $\left.\Delta R_{\text {dust }}+\Delta R_{\mathrm{veg}}\right)$. Grey and yellow shadings in $\Delta R_{\text {subtotal }}$ represent the lower and upper estimated uncertainty, respectively. Reconstructed temperature changes for comparison: (i) Antarctic $\Delta T_{\mathrm{EPICA}}$ from the EPICA Dome $\mathrm{C}$ ice core (Jouzel et al., 2007) on the EDC3 age scale (Parrenin et al., 2007) scaled with a constant polar amplification of two to a suggested change in global surface air temperature. (ii) Deep ocean $\Delta T_{\text {ocean }}$ deconvoluted from the benthic $\delta^{18} \mathrm{O}$ stack LR04 (Bintanja et al., 2005; Lisiecki and Raymo, 2005). 

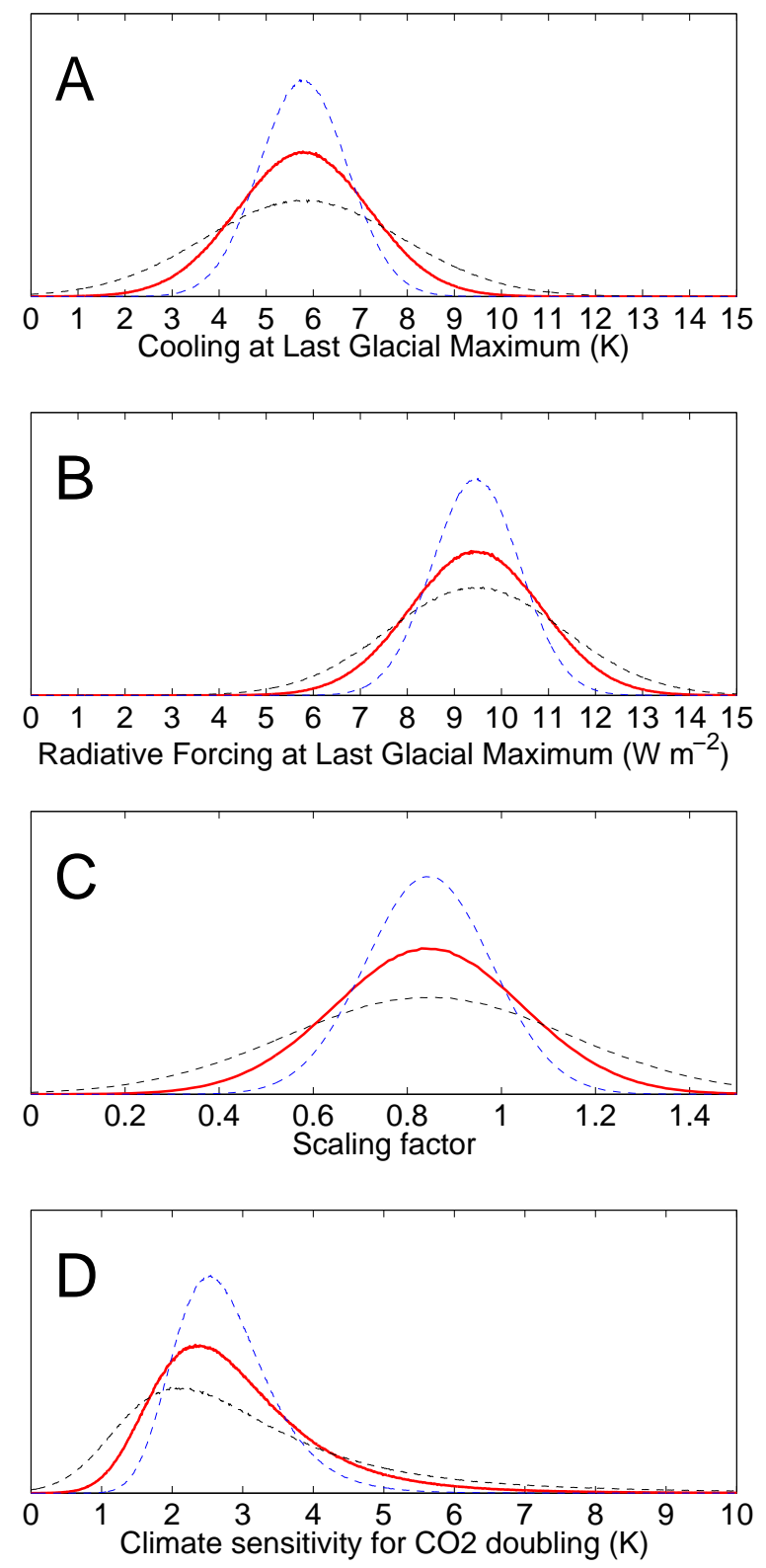

Figure 9: (A) Probability distribution of global cooling at the LGM. (B) Probability distribution of the LGM global radiative forcing relative to today from greenhouse gases, orbital forcing, ice sheets, vegetation and dust. (C) Uncertainty distribution in the scaling factor used to translate LGM climate sensitivity to present day sensitivity. (D) Probability distribution for present day equilibrium climate sensitivity for atmospheric $\mathrm{CO}_{2}$ doubling resulting from panels A-C. The estimated climate sensitivity includes the Planck, water vapour, lapse rate, sea ice/snow cover albedo and cloud feedbacks occurring on timescales of decades or less (equivalent to the climate model or Charney sensitivity) and is the quantity that is relevant for future climate projections on timescales of decades to centuries. The effects of ice sheets and vegetation changes are treated as a forcing. Red solid lines show the standard case as described in the text, while black and blue dashed lines show the distributions if all input uncertainties are increased by $50 \%$ or reduced by $33 \%$, respectively. For the radiative forcing in (B) the black and blue dashed lines represent the upper and lower estimated uncertainty $\left( \pm 1.9 \mathrm{~W} \mathrm{~m}^{-2}\right.$ and $\pm 0.9 \mathrm{~W} \mathrm{~m}^{-2}$, respectively), and the red solid line their mean value $\left( \pm 1.4 \mathrm{~W}^{-2}\right)$. 